\title{
ESSENTIAL WORK OF FRACTURE, CRACK TIP OPENING DISPLACEMENT, AND J-INTEGRAL RELATIONSHIP FOR A DUCTILE POLYMER FILM
}

\author{
A.B. Martínez, N. León*, D. Arencón, M. Sánchez-Soto \\ Centre Català del Plàstic, Departament de Ciència dels Materials i Enginyeria Metal- \\ lúrgica. Universitat Politècnica de Catalunya-BarcelonaTech. C/Colom 114, 08222, \\ Terrassa, Spain. \\ * noel.leon@estudiant.upc.edu \\ TIf: +34937837022 \\ Fax: +34937841827
}

\begin{abstract}
A unique set of double-edge notched tension specimens of a Polyethylene Terephthalate Glycol-modified film was tested in mode I, plane stress. The load was registered on a universal testing machine. The displacements, ligament lengths, and video frames were recorded by a Digital Image Correlation system. With these registered data, the essential work of fracture, J-integral, and crack tip opening displacement (CTOD) fracture concepts have been applied. The onset of crack initiation was through a complete yielded ligament. The analysis showed that the intrinsic specific work of fracture, $w_{e}$, is the specific energy just up to crack initiation, which is an initiation value. $w_{e}$ has both a coincident value and the same conceptual meaning as $J_{0}$, the $\mathrm{J}$-integral at the onset of crack initiation. The relationship between $J_{0}$ and CTOD is also determined. The influence on the notch quality when the specimens were sharpened by two different procedures, femtosecond laser ablation and razor blade sliding, was analysed in detail.
\end{abstract}

Keywords: Essential work of fracture, J-integral, polymer film. 


\section{Introduction}

One of the most important characteristics that make polymers such useful materials, especially in the packaging industry, is their ability to be manufactured into ductile films and thin sheets. When characterizing these materials, the tests for determining the mechanical properties are well established, but this is not the case for fracture properties.

The linear elastic fracture mechanics (LEFM) approach is used to study fractures occurring at nominal stresses well below the material yield stress. The main hypothesis of LEFM considers that the dissipated energy is confined in a small area near the crack tip (small-scale yielding) and the fracture is brittle, without extensive deformation.

LEFM is not applicable in cases where the crack propagation occurs through a highly deformed and yielded material. Instead, the J-integral, the crack tip opening displacement (CTOD), and the essential work of fracture (EWF) can be used to quantify fracture toughness. Although the J-integral method has been traditionally employed in materials with large plastic deformation surrounding the crack tip, the EWF approach is gaining popularity to characterize the plane stress toughness of ductile polymer films, basically using the double-edge notched tension (DENT) configuration, mainly due to the apparently simple preparation and easy testing of the DENT specimen. The extensive use of the EWF technique has been reviewed [1,2].

The intrinsic specific work of fracture, $w_{e}$, becomes an inherent material parameter only when the complete ligament yielding of the polymer sample precedes the onset of crack initiation. However, this condition is rarely met; in most articles it is not satisfied and $w_{e}$ is an apparent toughness that is only valid for comparison purposes. Nevertheless, it is known [2] that amorphous copolyesters such as PETG meet this condition, and it is certainly an excellent material for the EWF analysis.

To perform the notch sharpening in ductile polymer films, two different procedures are available: femtosecond laser ablation and razor blade sliding. In an earlier work on an ethylene-propylene block copolymer (EPBC) film, Martinez et al. [3] observed significant differences in the intrinsic essential work of fracture values when the femtolaser ablation and razor blade sliding techniques were applied, with the latter providing much higher values than the former one. The reason for this behaviour was associated with the accumulation of plastically deformed material at the tip of the razor blade sharpened notch and the almost negligible plastic deformation when the sharpening was realized by femtolaser ablation.

In a preceding EWF study [4] on an EPBC film, it was found that the $\mathrm{w}_{\mathrm{e}}$ value described the energy per unit ligament area just up to crack initiation, which is an initiation value. This conclusion leads to the question of whether this value is equivalent to $\mathrm{J}_{0}$ in plane stress because both parameters have the same physical meaning, good numerical agreement was usually found between $w_{e}$ and $J_{0}$, and other authors $[5,6]$ have proposed the equivalence between these parameters.

However, the EWF method still raises some questions, especially regarding the variations in the fracture parameters determined by different laboratories. It is suspected that these variations in the fracture parameters are originated by differences 
in the notch quality $[3,4]$. In addition, the relation between EWF and the J-integral is still not completely clear [5,6], because it is has not yet been answered if $w_{e}$ represents an initiation value, and there is only one clear evidence [1]. These questions indicate that the EWF procedure is not yet sufficiently defined to be considered as a standard.

The Digital Image Correlation (DIC) system compares random speckle patterns on the surface of the undeformed (reference) and deformed specimens or between any two specimen images representing two different deformation states. By applying this optical technique, it is possible to measure the deformation and the ligament length on the DENT specimens, allowing the EWF, CTOD, and J-integral analyses to be performed on a unique set of DENT specimens tested.

The first aim of the present work is to investigate the relationship between the $w_{e}, J_{0}$, and critical CTOD values and to obtain further clear evidence in another material, that $\mathrm{w}_{\mathrm{e}}$ is the specific energy just up to crack initiation, that is, an initiation value. The second aim is to investigate how the notch quality affects the fracture behaviour. The femtolaser and the razor blade sharpening produce notches of differing quality.

\section{Material and specimens}

This study was conducted on PETG, an amorphous thermoplastic copolyester with 1.4 cyclohexanedimethanol. The material was kindly supplied by Nudec (Spain) in the form of A4 size films with a nominal thickness, $t$, of $0.5 \mathrm{~mm}$.

Two kinds of specimens were prepared: dumbbell-shaped and DENT specimens. The tensile measurements were carried out on the dumbbell-shaped specimens (type 5 ISO 527-3) obtained in a cutting press.

The fracture tests were carried out on DENT specimens. These specimens were prepared by first cutting the films into rectangular coupons with $W=60 \mathrm{~mm}$ and $Z=90$ $\mathrm{mm}$ as shown in Figure 1. The rectangular coupons were carefully pre-notched to different ligament lengths, $I_{0}$, in a range between 5 and $20 \mathrm{~mm}$.

The sharpening of the pre-notches was accomplished by two different procedures, giving two sets of specimens to be tested separately.

In one set of specimens, the pre-notch was sharpened by femtosecond pulsed laser ablation (Femtolaser) using 120 -fs pulses at $795 \mathrm{~nm}$ with a repetition rate of $1 \mathrm{kHz}$. The system is based on a Ti: sapphire oscillator (Tsunami-Spectra Physics) plus a regenerative chirped pulse amplifier (Spitfire, Spectra Physics). The scanning speed was set as $130 \mu \mathrm{m} / \mathrm{s}$, the pulse energy was set as $0.07 \mathrm{~mJ}$, and eight passes were applied.

Femtosecond pulsed laser ablation has recently emerged as a powerful technique to micromachine practically any material with little thermal damage on the surface surrounding the ablated areas as compared to other laser processing procedures. This technique can remove the material of the notch tip by ablating it with almost no heat dissipation, preventing melting and thermal deformations of the surrounding area. 
Some of the femtolaser sharpened notches were observed by scanning electron microscopy (SEM). All the SEM micrographs were very similar to the image shown in Figure 2, having a sharpening extension of $300 \mu \mathrm{m}$ and a crack tip radius of $0.8 \mu \mathrm{m}$, both average values with very small deviations. Some minor thermal damage can also be observed at the crack tip. There is no sign of plastic deformation at the notch tip root.

In the second set of DENT specimens, the pre-notch was extended by the generalized contact method of sliding a new razor blade across the pre-notch tip in only one pass in order to follow the same track. Sharpening by razor blade sliding is an operatordependent technique, where the skill of the operator is important. The razor blade sharpened specimens have differences in extension, crack tip radius, and in plastic deformation at the crack tip as can be seen in the micrographs displayed in Figures $3 a$ and $3 b$. In Figure $3 b$, an accumulation of plastically deformed material in the crack tip can also be observed. It is possible to provide similar sharpening to that obtained by femtolaser.

The SEM observation of the notches involves destruction of the specimen and unfortunately these specimens cannot be tested.

\section{Testing devices and conditions}

All tests were performed at $23 \pm 1^{\circ} \mathrm{C}$ in a Zwick servo-hydraulic testing machine fitted with a two-camera DIC system. The frames were analysed using Aramis software (GOM, Germany). In all cases, a crosshead speed of $1 \mathrm{~mm} / \mathrm{min}$ was applied.

The DIC technique needs surfaces with high contrast to avoid image distortion and therefore inaccurate DIC data. Hence, after sharpening and before testing, one of the two surfaces of the transparent DENT specimens was covered with a thin white coating before being sprayed to obtain black points, producing the speckle pattern required by the DIC system.

The deformation behaviour study was implemented on the dumbbell-shaped specimens. The load was registered on the universal testing machine and the strain was measured on the DIC system frames by Aramis software.

The DENT specimens were loaded in the universal testing machine until complete failure and the load was registered. The DIC system images of each test were recorded for a later study of fracture evolution. The images were also analysed with Aramis software to measure the ligament length and deformation during the test event. With these registered data of loads versus displacements and ligament lengths versus displacements, it was possible to apply the EWF, CTOD, and J-integral methods later.

The original ligament length, $\mathrm{I}_{\mathrm{o}}$, of each specimen was measured after the test in an optical microscope. The displacements were measured by using as reference two points located very close together across the sharpened notch and taking into account the fact that the Outer Plastic Zone (OPZ) was contained between these two points. The initial distance between the two reference points was constant for all the specimens. 


\section{Deformation behaviour}

The uniaxial tensile yield stress $\left(\sigma_{y}\right)$, modulus $(E)$, and Poisson's ratio $(v)$ of the PETG material were measured on the dumbbell-shaped specimens.

The tensile stress-strain curves, represented in Figure 4, show an extensive amount of plastic deformation. It is possible to see a yield point (maximum load) where necking starts, followed by a sudden drop in load where the neck develops. Afterwards, there was a drawing of the necked region (cold drawing) during which the deformation continued at a constant stress level (engineering flow stress).

The results obtained from the tensile test are: $E=1.89 \pm 0.5 \mathrm{GPa}, \sigma_{\mathrm{y}}=51 \pm 1.5 \mathrm{MPa}$, $\sigma_{\mathrm{fs}}$ (engineering flow stress) $=34.4 \pm 1.2 \mathrm{MPa}$, and $\mathrm{v}=0.42$.

\section{The Essential Work of Fracture (EWF) analysis}

The EWF method was firstly proposed by Cotterell and Reddell [7], after Broberg's work on stable crack growth [8]. It is based on the hypothesis that the total energy involved in the ductile fracture of a pre-cracked specimen $\left(\mathrm{W}_{\mathrm{f}}\right)$ can be separated into two terms:

$W_{f}=W_{e}+W_{p}$

where $\mathrm{W}_{\mathrm{e}}$, called the 'essential work of fracture', represents the energy required for the creation of two new surfaces during the crack propagation, whereas the second term, $W_{p}$, is called the plastic work or non-essential work of fracture and collects all other sources of energy produced throughout the fracture (plastic deformation around the crack, heat dissipation, etc.). The term $W_{e}$ is considered to be proportional to the area of the Fracture Process Zone (FPZ), while $W_{p}$ is proportional to the volume of the OPZ. These zones are schematized in Figure 1 for a DENT specimen.

Rewriting Equation 1 using the specific terms (i.e. dividing all terms by the area of the ligament cross-section) gives the following expression:

$w_{f}=\frac{W_{f}}{l_{o} \cdot t}=w_{e}+\beta w_{p} \cdot l_{o}$

where $t$ is the specimen thickness, $I_{0}$ is the ligament length, and $\beta$ is a factor that depends on the OPZ's shape. Equation 2 allows the determination of the fracture parameters $w_{e}$ and $\beta w_{p}$ by plotting the specific fracture energy, $w_{f}$, of a series of DENT specimens as a function of their ligament length. $w_{e}$ is the intercept at the origin and $\beta w_{p}$ is the slope of the regression line. A more detailed description of the procedure can be found elsewhere $[1,2]$.

In the EWF analysis, the following key assumptions are made:

a) The ligament length is fully yielded prior to the onset of crack propagation. Full ligament yielding must show a load drop in the related load-displacement curves. This requirement ensures that the fracture mechanism is the same irrespective of the ligament length. 
b) Fracture occurs under plane stress conditions.

c) Identical sharp notches without plastic deformation, such as material accumulation, at the crack tip. This requirement guarantees self-similar load-displacement curves of the test specimens with different ligament lengths. Self-similarity can be also obtained in other cases when the ligament yielding occurs simultaneously with crack growth.

In order to meet the plane stress conditions in the specimen ligament length, the following restrictions must be fulfilled:

a) $I_{0} \geq 3$ or $5 t$

This condition guarantees that the state of stress is pure plane stress.

b) $\mathrm{I}_{\mathrm{o}}<2 \mathrm{r}_{\mathrm{p}}$

where $r_{p}$ is the plastic zone radius. This equation ensures complete ligament yielding prior to the crack growth, and $r_{p}$ can be obtained through:

$2 r_{p}=\frac{\pi}{8}\left(\frac{E w_{e}}{\sigma_{y}^{2}}\right) \quad$ for a linear plastic zone

$2 r_{p}=\left(\frac{E w_{e}}{\pi \sigma_{y}^{2}}\right) \quad$ for a circular plastic zone

where $E$ is the elastic modulus, $\sigma_{y}$ is the uniaxial tensile yield stress, and $w_{e}$ is the intrinsic specific essential work of fracture.

c) $\mathrm{I}_{0} \leq \mathrm{W} / 3$

to prevent edge effects.

The DENT specimens were tested. The servo-hydraulic testing machine was used to measure the applied load, and the displacements were simultaneously measured by the DIC system using two constant distance reference points as explained above.

The registered load-displacement curves are shown in Figures $5 \mathrm{a}$ and $5 \mathrm{~b}$ for the femtolaser and razor blade sharpened specimens, respectively. A careful observation of the frames stored by the DIC system shows that in several razor blade sharpened specimens, the two side notches of the same specimen did not propagate simultaneously. In these specimens some of their corresponding load-displacement curves accomplish self-similarity but were rejected and are not represented in Figure $5 \mathrm{~b}$. This non-simultaneous propagation is attributed to differences between side notches. In the other razor blade sharpened specimens, the load-displacement curves also did not accomplish the requirement of similarity, probably due to notch differences between specimens, and thus they were eliminated. In Figure 5b, only the samples that meet the self-similarity condition are depicted.

In the entire test on the femtolaser sharpened specimens, both side notches propagate simultaneously; further, all the registered load-displacement curves have self-similarity, are valid, and are thus represented in Figure 5a. The femtolaser notch sharpening is a 
non-contact technique that is not operator-dependent and it aims to generate identical sharpening with little thermal damage and without plastic deformation in front of the crack tip.

The numerical integration of the load-displacement plots of Figures $5 \mathrm{a}$ and $5 \mathrm{~b}$ gives the work of fracture, $W_{f}$. The specific work of fracture $w_{f}$ is found when the work of fracture is divided by the original ligament surface. The specific work of fracture as a function of the original ligament length obtained by the femtolaser and the razor blade sharpened specimens are plotted in Figures $6 a$ and $6 \mathrm{~b}$, respectively. From linear regression, $w_{e}$, the intercept at the origin and the slope $\beta w_{p}$ are found, as indicated by Equation 2.

The EWF parameters are practically equivalent regardless of the notch sharpening procedure after all invalid razor blade notch sharpened specimens have been discarded from the analysis. The intrinsic specific essential work of fracture values, 32.36 and $31.69 \mathrm{~kJ} / \mathrm{m}^{2}$, agree very well with the values obtained by others authors on the same material, which are summarized by Bárány et al. [2].

A new plot can help us to clarify the EWF analysis. If the load for each ligament length in Figure 5 is divided by its initial ligament section, a representation of nominal stress versus displacement, $\sigma_{n}-d$, is achieved in Figures $7 a$ and $7 b$ for both sharpening procedures. Here, a set of overlapping curves (heads) is observed in the low displacement range up to a fairly well recognizable displacement value, $d_{i}$, from which the curves (tails) start to diverge. The hatched area under the $\sigma_{n}-d$ curves in Figure 7 is equal to the aforementioned $w_{\mathrm{e}}$ value, and the displacement range over which this value works begins from $d=0$ and continues up to the measured displacement at the end of this area where the curves depart from one other, $d_{i}$. From these observations, we identify this displacement value $\left(\mathrm{d}_{\mathrm{i}}\right)$ with the crack initiation displacement and $\sigma_{\mathrm{i}}$ as the crack initiation stress. The hatched area represents the energy up to crack initiation and then $w_{e}$ corresponds to the initiation energy, the energy per surface unit required to create two new surfaces in a cracked body submitted to an external load. An identical behaviour was found previously [4] in an EPBC polymer film.

In the uniaxial tensile test, the stress-strain curves overlap if the distance between the displacement reference points is constant for all the specimens and the yielding occurs inside the displacement reference points, and the same is true for the heads in Figures $7 \mathrm{a}$ and $7 \mathrm{~b}$. In the DENT tests, we measured the displacements used as two reference points located near the initial sharpened notch, which contained just the OPZ zone inside. The distance between the reference points was constant for all the specimens. Thus, the elastic and viscoelastic contributions due to the bulk polymer sample outside the fracture process are practically negligible. These contributions affect both the displacements and the energies. The slope $\beta w_{p}$ of the plot of $w_{f}$ versus $I_{o}$ is affected [3] by the distance between the displacement reference points.

In a careful observation of the frames recorded by the DIC system, we were not able to distinguish with precision the frame at which blunting finishes and the crack initiation begins. The recorded frame shown in Figure 8 accounts for the point $A$ in Figure $7 a$ and corresponds to the largest original ligament length $(13.01 \mathrm{~mm})$ tested. This frame is clearly indicative of full ligament yielding before crack initiation. The plastic zone in 
this frame is wedge-shaped and very narrow. These observations are consistent in all valid specimens, in fact.

It is important to note that the heads of the curves of net stress versus displacement (Figure 7) closely resemble those of the uniaxial tensile tests displayed in Figure 4, including the stress drop characteristic of the necking before $\mathrm{d}_{\mathrm{i}}$, the displacement at the onset of crack initiation. For the femtolaser and razor blade sharpened specimens (Figures $7 \mathrm{a}$ and $7 \mathrm{~b}$ ), the maximum values of net stress, 50.61 and $47.01 \mathrm{MPa}$, are comparable to the uniaxial tensile yield stress, $51 \mathrm{MPa}$, and the $\sigma_{i}$ values, 35.34 and 31.45 MPa, might be $34.40 \mathrm{MPa}$, the value of the engineering flow stress, if we take into account the experimental variability.

From the specific intrinsic work of fracture, the uniaxial tensile yield stress, and the elastic modulus, the linear plastic zone radius has been calculated using Equation 3, resulting in $2 r_{p}=9.28 \mathrm{~mm}$, but we have used valid original ligament lengths comprised between 5 and $13 \mathrm{~mm}$.

Although Equation 3 is a reasonable size criterion, it appears to be too restrictive considering the evidence visually observed in Figure 8 and that indicated by the net stress drop before $\mathrm{d}_{\mathrm{i}}$, in Figures $7 \mathrm{a}$ and $7 \mathrm{~b}$. Barany et al. [2] noted that this criterion is too restrictive when applied to amorphous copolyesters.

The key assumptions for the EWF analysis are thoroughly satisfied for the femtolaser and razor blade sharpened specimens because the ligament length is completely yielded before the onset of crack initiation. Furthermore, the specimens meet the plane stress conditions, and the initial ligament length of all the specimens is larger than five times the thickness. Then the $\mathrm{w}_{\mathrm{e}}$ represents an inherent PETG property.

The sequence of events leading to fracture of the DENT specimens is encompassed in the opening and blunting of the notch with the yielding of the ligament area (heads) followed by the crack initiation and propagation until complete fracture (tails). This fracture process is represented in Figure 9 , where $I_{\text {we }}$ is the ligament length at $d_{i}, I_{i}$ is the measured ligament length during the test, and $\Delta a_{b}$ is the crack length increment due to blunting.

The plastic deformation in front of the crack tip might originate a reduction in $\mathrm{w}_{\mathrm{e}}$ because less energy may be necessary during the blunting, and this may explain the slightly smaller $w_{e}$ value obtained for the razor blade sharpened specimen in comparison with the femtolaser value. In the toughest materials, it is possible to generate a plastic accumulation of material at the crack tip [3], as shown in Figure 3b, resulting in a local increase of the crack tip surface. Then if the crack initiates when $\sigma_{i}$ at the crack tip occurs, a larger value of the load will be necessary for the notches with the plastic accumulation to reach $\sigma_{i}$ locally at the crack tip, resulting in an increasing $\mathrm{w}_{\mathrm{e}}$. This can explain the anomalous behaviour of some razor blade sharpened specimens that are not propagated at the same time.

The DIC system images recorded in the DENT test of each specimen were analysed with Aramis software to measure the ligament length, $\mathrm{l}_{\mathrm{i}}$, and their displacement in each frame. Thus the data of the ligament versus the displacement for each specimen were obtained. These data are represented in Figures 10a and 10b for each set of 
femtolaser and razor blade sharpened specimens, respectively. The ligament length versus displacement curves which did not have self-similarity were also discarded.

Self-similarity of the $\sigma_{\mathrm{n}}-\mathrm{d}$ plots (Figures $7 \mathrm{a}$ and $7 \mathrm{~b}$ ) and the ligament length versus displacement plots (Figures 10a and 10b) is the best way to elucidate the validity of a tested specimen. After this analysis, which eliminated the specimens with poor quality notches, the resulting $w_{e}$ values for both sets of sharpened specimens are practically identical.

It is possible to analyse the crack propagation, as well. When the ligament is completely yielded and necked, the load $P$ is a function of the crack length and is represented by

$P=t(W-a) \sigma_{i}$

And its derivative is

$\frac{d P}{d a}=-t \sigma_{i}$

Then, if we represent the load as a function of the crack length, a straight line with a slope $-t \sigma_{i}$ should be found.

As the crack length, $a$, is given (Figure 9) by

$a=W-l_{i}$

then, by combining Equation 7 with Figures 5 and 10, we can represent the load as a function of the length for the tails in Figure 11a for the femtolaser and in Figure $11 \mathrm{~b}$ for the razor blade sharpened specimens. The linear dependence can be observed and from the slope we found the $\sigma_{i}$ values of 36.98 and $32.16 \mathrm{MPa}$ for the femtolaser and razor blade sharpened specimens, respectively. These values are practically equal to the $\sigma_{i}$ values of 35.34 and $31.45 \mathrm{MPa}$ found before in Figures $7 \mathrm{a}$ and $7 \mathrm{~b}$ for the femtolaser and razor blade sharpened specimens. All the propagations follow the same trend except at the higher crack length values, near the complete specimen fracture, where the slope and hence $\sigma_{i}$ increase, probably due to orientation hardening.

In a single eventual graph for Figures $11 \mathrm{a}$ and $11 \mathrm{~b}$, it is evident that the curves will overlap well enough considering the experimental variability. At this point, it is convenient to remark that the crack propagation is independent of the notch sharpening technique, as has been previously observed $[3,4]$.

\section{The crack tip opening displacement}

Another important fracture mechanics concept first proposed by Wells [9] is the CTOD. This method is used to determine a fracture mechanics parameter for ductile materials. Essentially it measures the resistance of a material to the propagation of a crack. There 
is a critical value $\mathrm{CTOD}_{\mathrm{c}}$ of the crack tip opening displacement, where the crack initiates propagation.

It has been shown that for plane stress DENT specimens exist a linear relationship [5] between the displacement at complete rupture, $d_{r}$, and the original ligament length, $I_{0}$.

$d_{r}=C T O D_{c}+\alpha \cdot l_{o}$

where $\alpha$ is the propagation contribution to the extension.

The $\mathrm{CTOD}_{\mathrm{c}}$ can be obtained extrapolating the regression line of Equation 8 to zero ligament length.

In our opinion, Equation 8 is only valid when there is no contribution to the displacement of the outside part of the OPZ zone.

The displacements at rupture versus $I_{0}$ for the femtolaser and razor blade sharpened specimens are plotted in Figures $12 a$ and $12 b$, respectively. Clearly there is a linear relationship and the intercept at the origin of the regression line gives the results for the $\mathrm{CTOD}_{\mathrm{c}}$ values of $0.98 \mathrm{~mm}$ and $0.83 \mathrm{~mm}$ for the femtolaser and the razor blade sharpened set of specimens, respectively. As expected, these CTOD $_{c}$ values are coincident with the $d_{i}$ values found in Figures $7 \mathrm{a}$ and $7 \mathrm{~b}$. Both methods and both notch sharpening techniques provide virtually the same experimental $C T O D_{c}$ results.

\section{The $\mathrm{J}$ analysis}

Based on the deformation theory of plasticity, Cherepanov [10] and Rice [11] developed a new fracture parameter, the J-integral. This theoretical concept represents an energy contour path integral that is independent of the path around the crack.

Rice [11] showed that the J-integral is essentially equal to the energy release rate of work done on a nonlinear elastic body containing a crack per unit surface area of crack growth, which can be expressed as

$J=-\frac{1}{t}\left(\frac{d U}{d a}\right) d=c t e$

where $\mathrm{U}$ is the external work done up to a given constant displacement, $\mathrm{d}$, and $\mathrm{a}$ is the crack length.

There are several approaches to evaluating the J-integral [12], but for the sake of simplicity, the Begley and Landes experimental method [13] is used here because it can be adequately applied to the previous EWF test results.

This experimental method requires two steps. The first step consists in the graphical representation of the energy divided by the specimen thickness as a function of the crack length when the displacement is fixed. The method consists in taking a constant displacement value $d$, in Figure 10, where only one $l_{i}$ value is found for each specimen; then, using Equation 7, each $I_{i}$ value is transformed into a crack length value. The energy is found by numerical integration of the load over the constant displacement 
value $d$ in Figure 5. The same procedure is applied to a new set of constant displacements adequately chosen. This graphical representation is shown in Figures $13 \mathrm{a}$ and $13 \mathrm{~b}$ for both sets of specimens. The points belonging to the same displacement show linearity and can be adjusted by a straight line. Following Equation 9 , the slope of the regression lines is $-J$.

The second step consists in the representation of the $\mathrm{J}$ values versus displacement as shown in Figures $14 \mathrm{a}$ and $14 \mathrm{~b}$ for the femtolaser and the razor blade set of specimens.

Following Hodgkinson and Williams [14], the total energy $U$ for a non-work-hardening full yielding of the ligament is

$U=P . d$

which, combined with Equation 5, results in

$U=t(W-a) \sigma_{i} \cdot d$

That is, $\mathrm{U} / \mathrm{t}$ is a linear function of the crack length at constant fixed displacement, and this is verified in Figures $13 a$ and $13 b$ for both set of specimens.

Equation 9 merged with Equation 11 gives

$J=-\frac{1}{t}\left(\frac{d U}{d a}\right) d=c t e=\sigma_{i} \cdot d$

From the slopes of the regression lines in Figure 13 and the slopes in Figure 14, the verification of Equation 12 is confirmed for both set of specimens. The $\sigma_{i}$ values calculated from the slopes of 36.71 and $34.81 \mathrm{MPa}$ for the femtolaser and the razor blade set of specimens match the $\sigma_{i}$ values found before reasonably well, taking into account the specimen variability and the large data treatment.

The $\mathrm{J}$ value at crack initiation, $\mathrm{J}_{\mathrm{o}}$, is obtained by introducing the $\mathrm{CTOD}_{\mathrm{c}}$ in the $\mathrm{J}$-integral curves, as shown in Figure 14. The resulting values of 29.13 and $31.37 \mathrm{~kJ} / \mathrm{m}^{2}$ for the femtolaser and the razor blade set of specimens, respectively, match their previously found related $\mathrm{w}_{\mathrm{e}}$ values of 32.26 and $31.69 \mathrm{~kJ} / \mathrm{m}^{2}$ very well.

The Shih analysis [15] shows that there is a unique relationship between $\mathrm{J}_{0}$ and the critical value of the crack tip opening displacement $\left(C T O D_{c}\right)$. For a non-hardening material in plane stress, assuming that the stress in the plastic zone is $\sigma_{i}$, then

$J_{o}=\sigma_{i} \cdot C T O D_{c}$

In our material, $w_{e}=J_{0}$, and this relationship (Equation 13) is entirely fulfilled in our experimental results.

\section{Conclusions}

The femtosecond ablation laser technique generates repetitive sharp notches, with similar extensions, a notch tip radius without plastic deformation, and little thermal 
damage at the notch root, and as result it is more suitable than the razor blade sliding technique.

In the razor blade sharpened specimens, the differences between the side notches of the same specimen or the differences in the notch quality between specimens result in a loss of the self-similarity in both net stress and ligament length versus displacement curves. If these specimens without self-similarity are not discarded, then large the $w_{e}$ value is.

Observation of the $\sigma_{n}-d$ and $l_{i}-d$ plots is the best way to eliminate specimens with anomalous fracture behaviour due to their bad notch quality.

The repeatability and the reproducibility of the DENT tests depend on the quality of the notches.

In this polymeric film, the ligament was fully yielded before the onset of crack initiation. It is demonstrated that $w_{e}$ is the specific energy just up to crack initiation, this is, an initiation value. $w_{e}$ and $J_{0}$ have the same conceptual meaning and both are inherent material properties.

The $w_{e}$ and $J_{0}$ values are coincident and it is confirmed that $w_{e}$ is equivalent to $J_{0}$ in plane stress when the ligament is completely yielded before the onset of crack initiation.

The use of the DIC system allowed the EWF, CTOD, and J-integral techniques to be applied successfully to a unique set of specimens, resulting a complete relationship between $\mathrm{w}_{\mathrm{e}}, \mathrm{J}_{\mathrm{o}}$, and $\mathrm{CTOD}_{\mathrm{c}}$.

In the DENT test, the plot of nominal stress versus displacement allows the energy to be separated into two parts: the energy needed for crack initiation and the propagation energy.

\section{Acknowledgements}

Authors acknowledge to Ministerio de Economia y Competitivad of Spain for their financial support through the project MAT2012-37762-C02-01. N. León expresses his gratitude to the National Council for Science and Technology (CONACYT) based in Mexico for the economic support to make possible this Ph.D. thesis.

\section{References}

1. A.B. Martínez, J. Gamez-Perez, M. Sanchez-Soto, J.I. Velasco, O.O. Santana, M.LI Maspoch. The Essential Work of Fracture (EWF) method. Analyzing the Post-Yielding Fracture Mechanics of polymers. Eng Fail Anal 2009; 16(8): 2604.

2. T. Bárány, T. Czigány, J. Karger-Kocsis. Application of the essential work of fracture (EWF) concept for polymers, related blends and composites: A review. Prog Polym Sci 2010; 35(10): 1257. 
3. A.B. Martínez, A. Segovia, J. Gamez-Perez, M.LI Maspoch. Influence of femtolaser notch sharpening technique in the determination of essential work of fracture (EWF) parameters. Eng Fract Mech 2009; 76(9): 1247.

4. A.B. Martínez, A. Segovia, J. Gamez-Perez, M.LI Maspoch. Essential work of fracture analysis of the tearing of a ductile polymer film. Eng Fract Mech 2010; 77(14): 2654.

5. Y.W. Mai, P. Powell. Essential work of fracture and j-integral measurements for ductile polymers. J Polym Sci B Polym Phys 1991; 29(7): 785.

6. M. Rink, L. Andena, C. Marano. The essential work of fracture in relation to Jintegral. Eng Fract Mech 2014; 127: 46.

7. B. Cotterell, J.K. Reddel. The essential work of plane stress ductile fracture. Int J Fract 1977; 13(3): 267.

8. K.B. Broberg. On stable crack growth. J Mech Phys Solids 1975; 23(3): 215.

9. A.A. wells. Application of fracture mechanics at and beyond general yielding. $\mathrm{Br}$ Weld J 1963; 10: 563.

10. G.P. Cherepanov. Crack propagation in continuous media. J Appl Math Mech 1967; 31(3): 476.

11. J.R. Rice. A path independent integral and the approximate analysis of strain concentration by notches and cracks. J Appl Mech 1968; 35: 379.

12. X.K. Zhu, J.A. Joyce. Review of fracture toughness (G, K, J, CTOD, CTOA) testing and standardization. Eng Fract Mech 2012; 85: 1.

13. J.A. Begley, J.D. Landes. The $\mathrm{J}$ integral as a fracture criterion. In: Fracture toughness, ASTM STP 514, American Society for Testing and Materials, Philadelphia, 1972. P. 1-20.

14. J.M. Hodgkinson, J.G. Williams. J and $G_{c}$ analysis of the tearing of a highly ductile polymer. J Mater Sci 1981; 16(1): 50.

15. C.F. Shih. Relationships between the J-integral and the crack opening displacement for stationary and extending cracks. J Mech Phys Solids 1981; 29(4): 305. 


\section{FIGURE CAPTIONS}

Figure 1. Scheme showing the DENT specimen geometry.

Figure 2. SEM micrograph of femtolaser sharpened notch.

Figure 3. SEM micrographs of razor blade sharpened notches: a) Slight plastic deformation at the notch root, b) Large plastic deformation including material accumulation at the notch root.

Figure 4. Stress-strain curves from uniaxial tensile tests.

Figure 5. Load-displacement curves: a) Femtolaser sharpened, b) Razor blade sharpened.

Figure 6. EWF plot: a) Femtolaser sharpened, b) Razor blade sharpened.

Figure 7. New plot $\sigma_{n}-\delta$ : a) Femtolaser sharpened, b) Razor blade sharpened.

Figure 8. Frame of the point $A$ in figure $7 a$ which displays a completely yielded ligament before crack propagation.

Figure 9. Schematic DENT test evolution.

Figure 10. Tracking of the ligament length evolution during fracture testing: a) Femtolaser sharpened, b) Razor blade sharpened.

Figure 11. Plot of load (tails) versus crack length: a) Femtolaser sharpened, b) Razor blade sharpened.

Figure 12. Determination of $\mathrm{CTOD}_{\mathrm{c}}$ : a) Femtolaser sharpened, b) Razor blade sharpened.

Figure 13. Input energy versus crack length: a) Femtolaser sharpened, b) Razor blade sharpened.

Figure 14. J-integral plot: a) Femtolaser sharpened, b) Razor blade sharpened. 


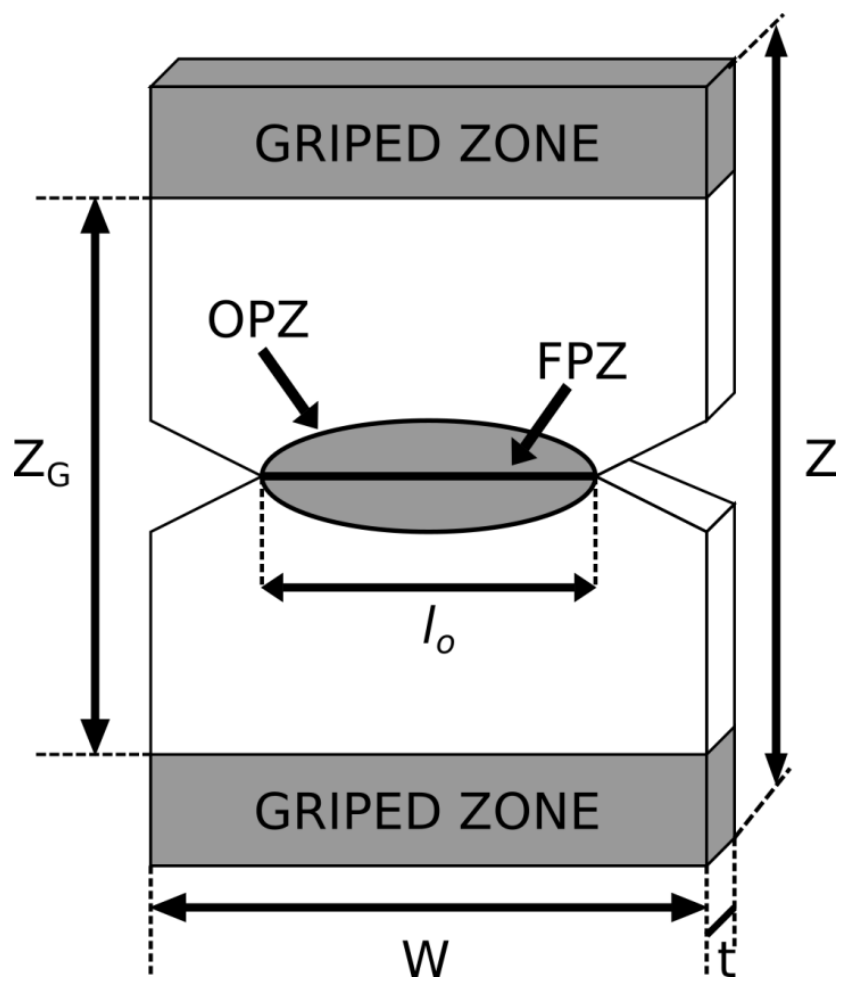

Figure 1 


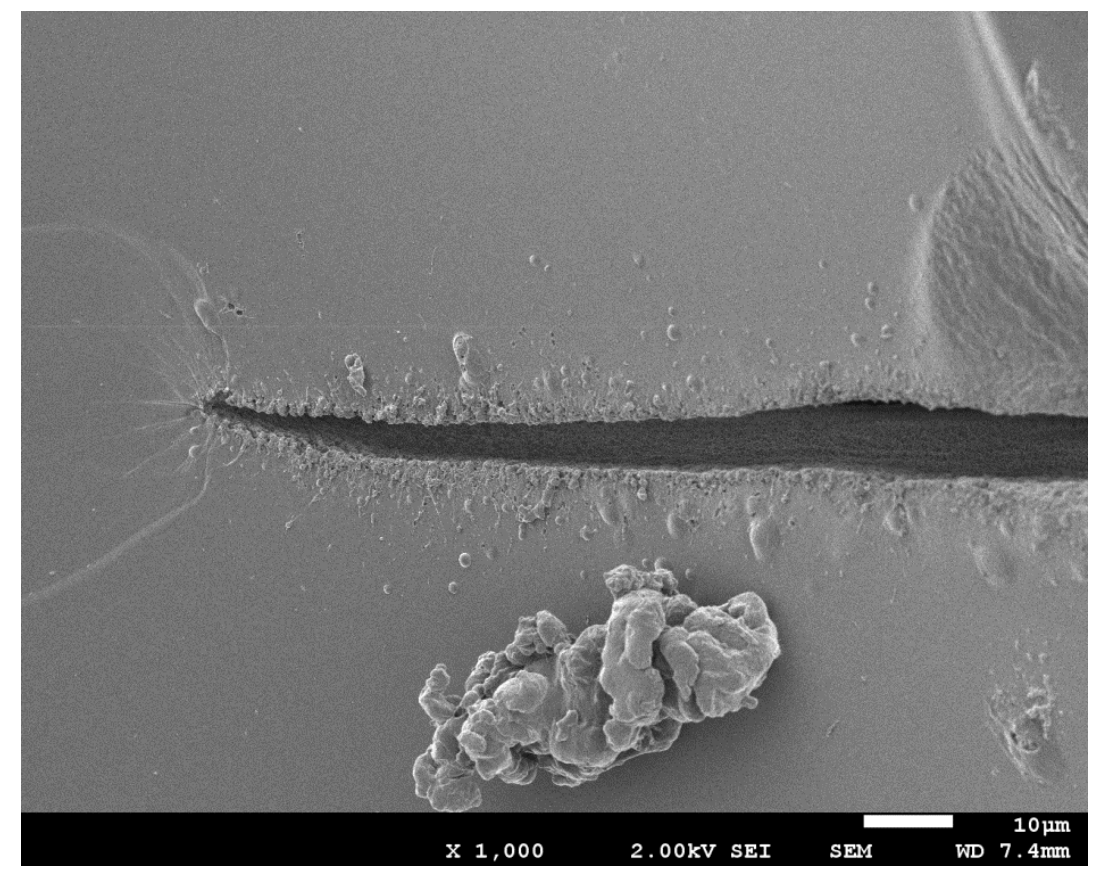

Figure 2 


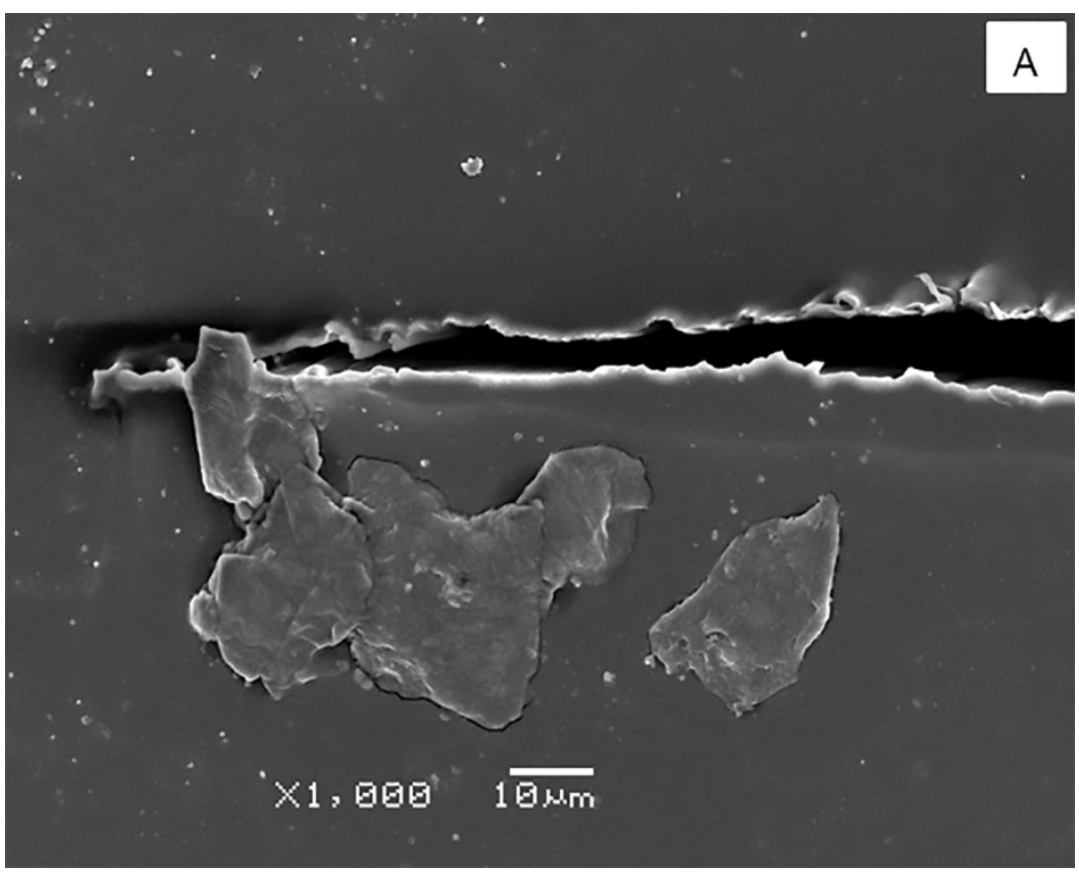

Figure $3 a$ 


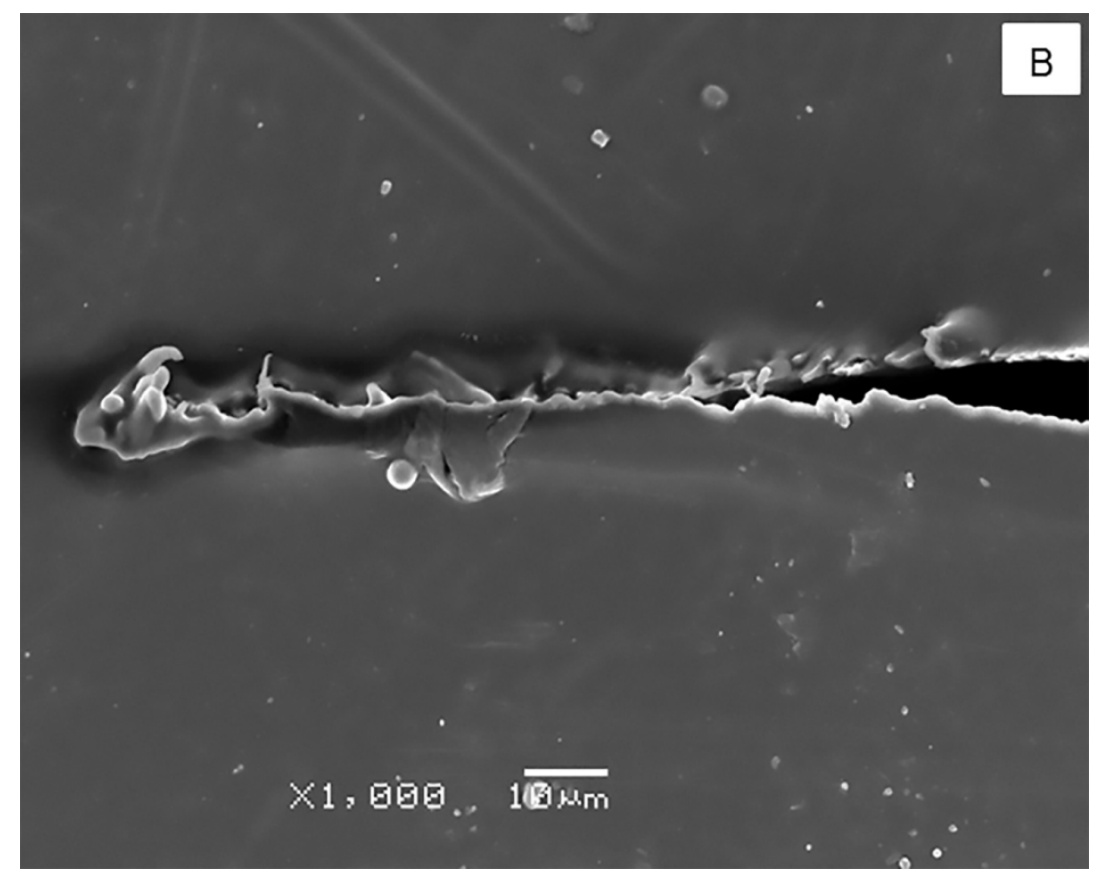

Figure $3 b$ 


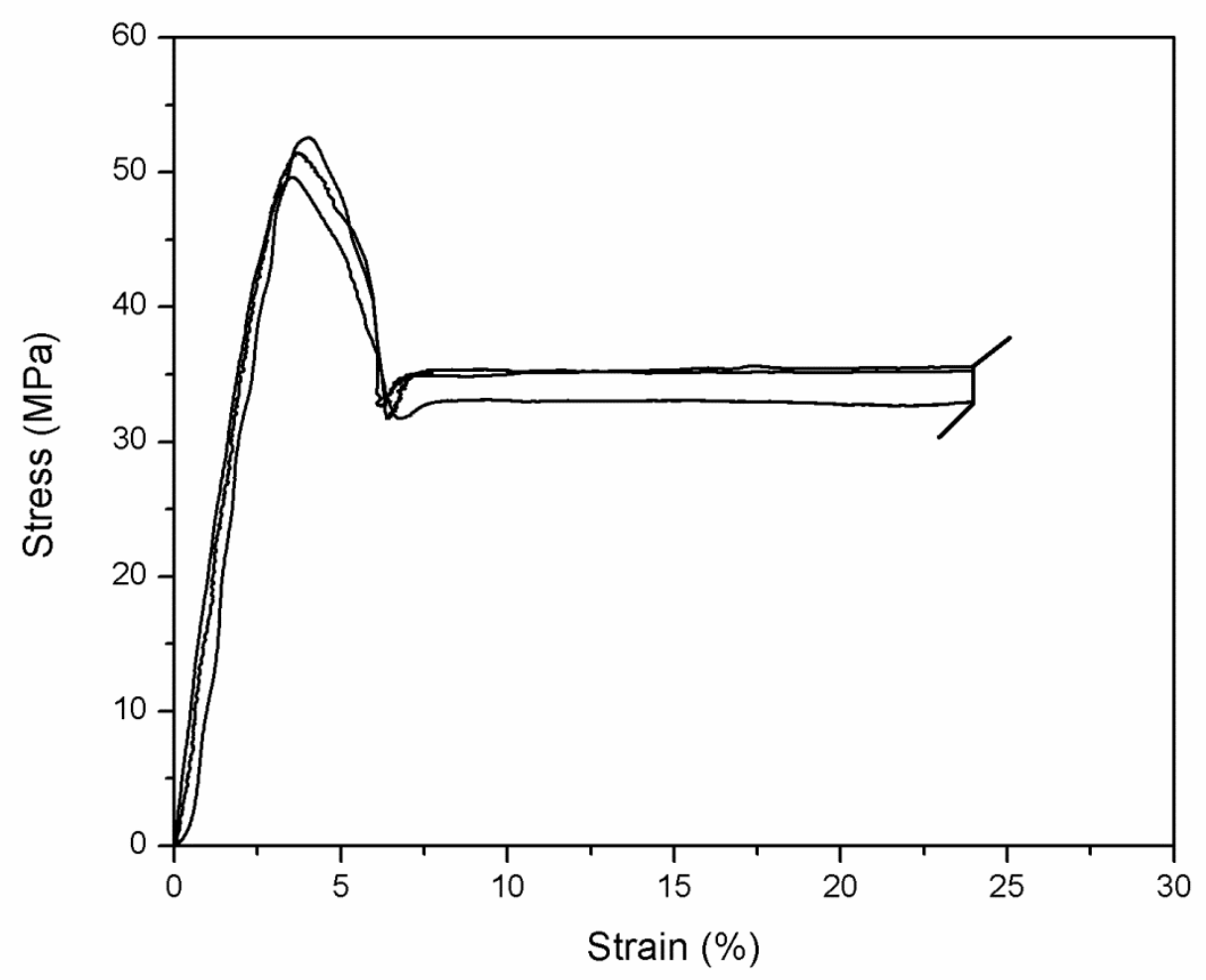

Figure 4 


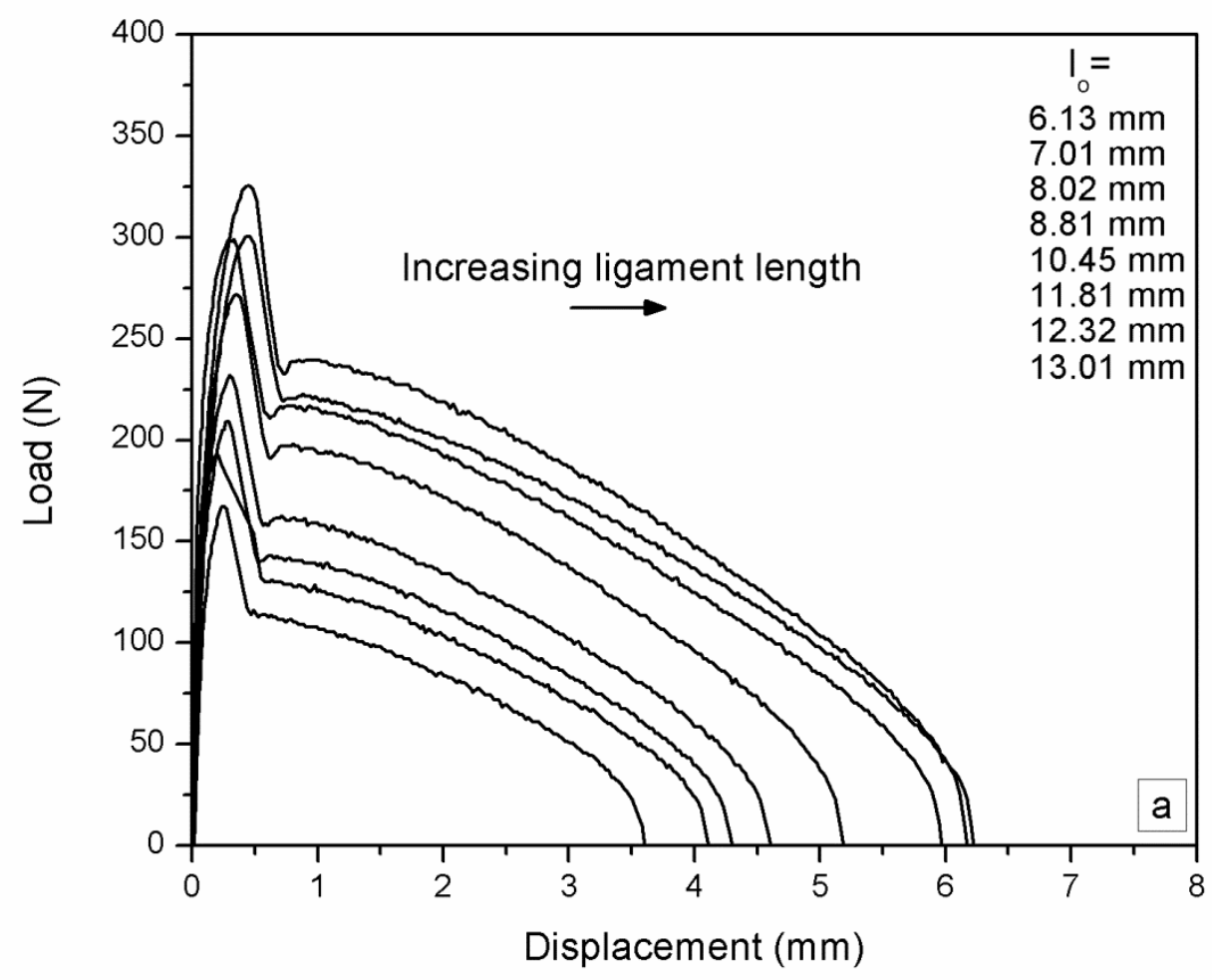

Figure 5a 


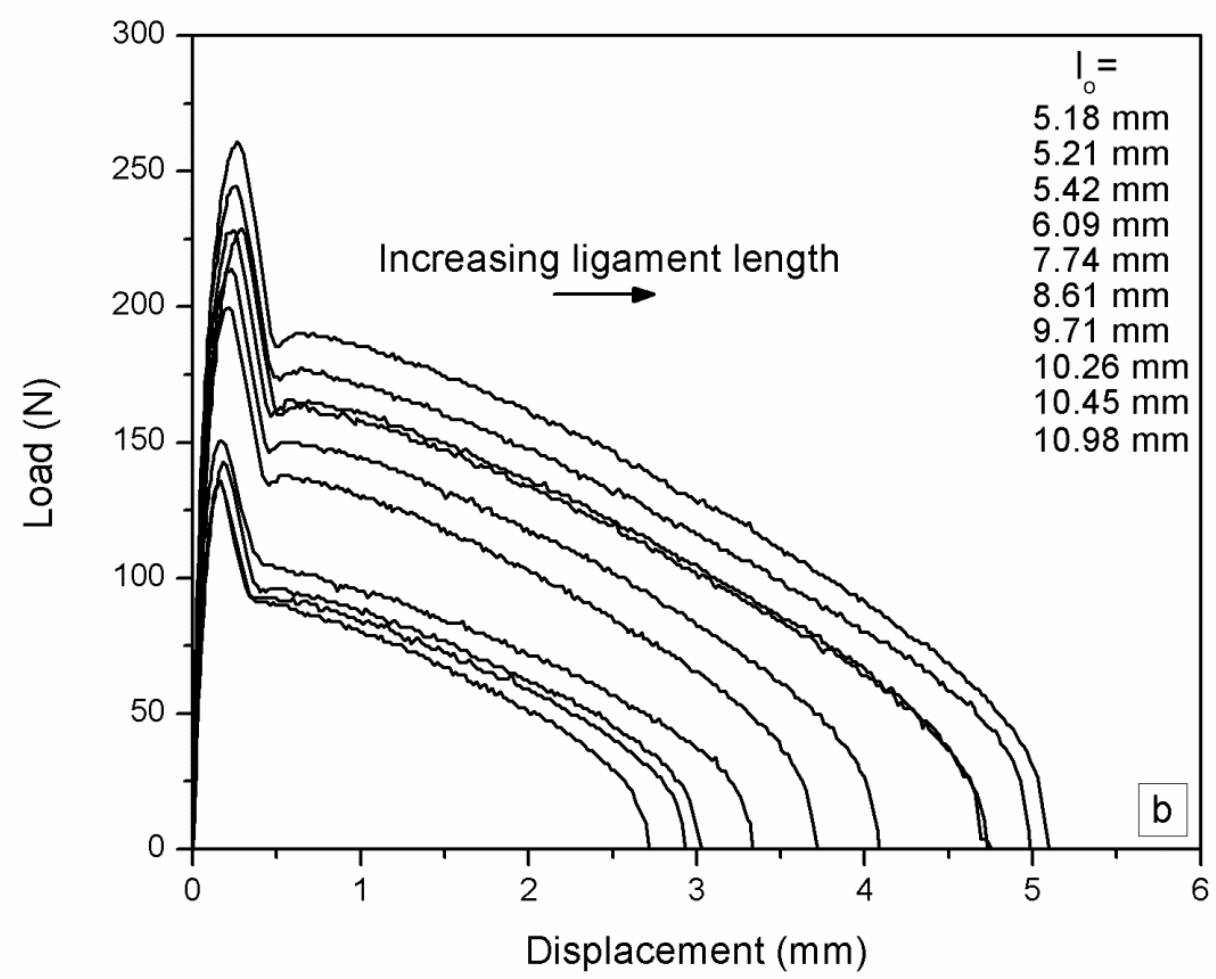

Figure $5 b$ 


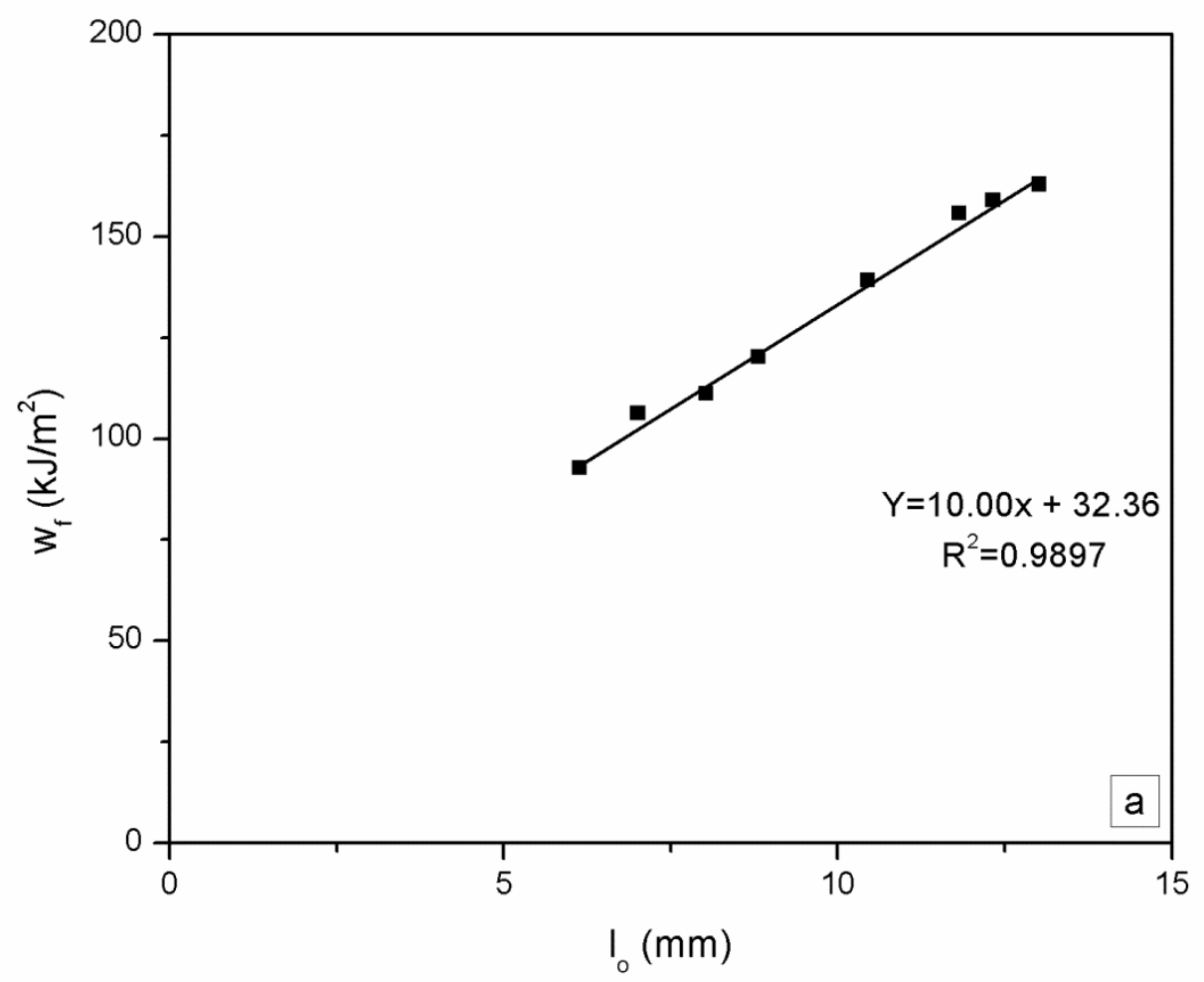

Figure $6 a$ 


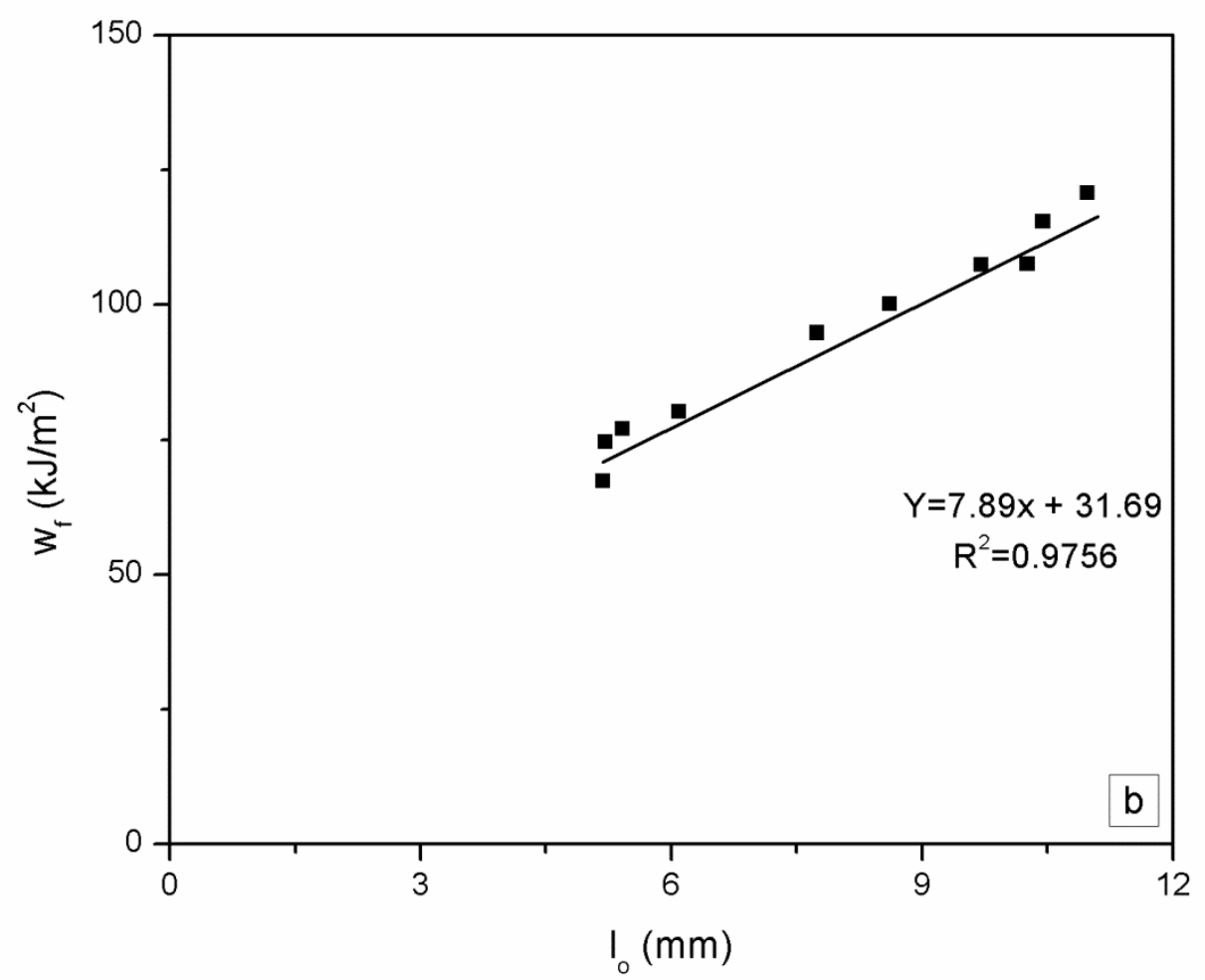

Figure $6 b$ 


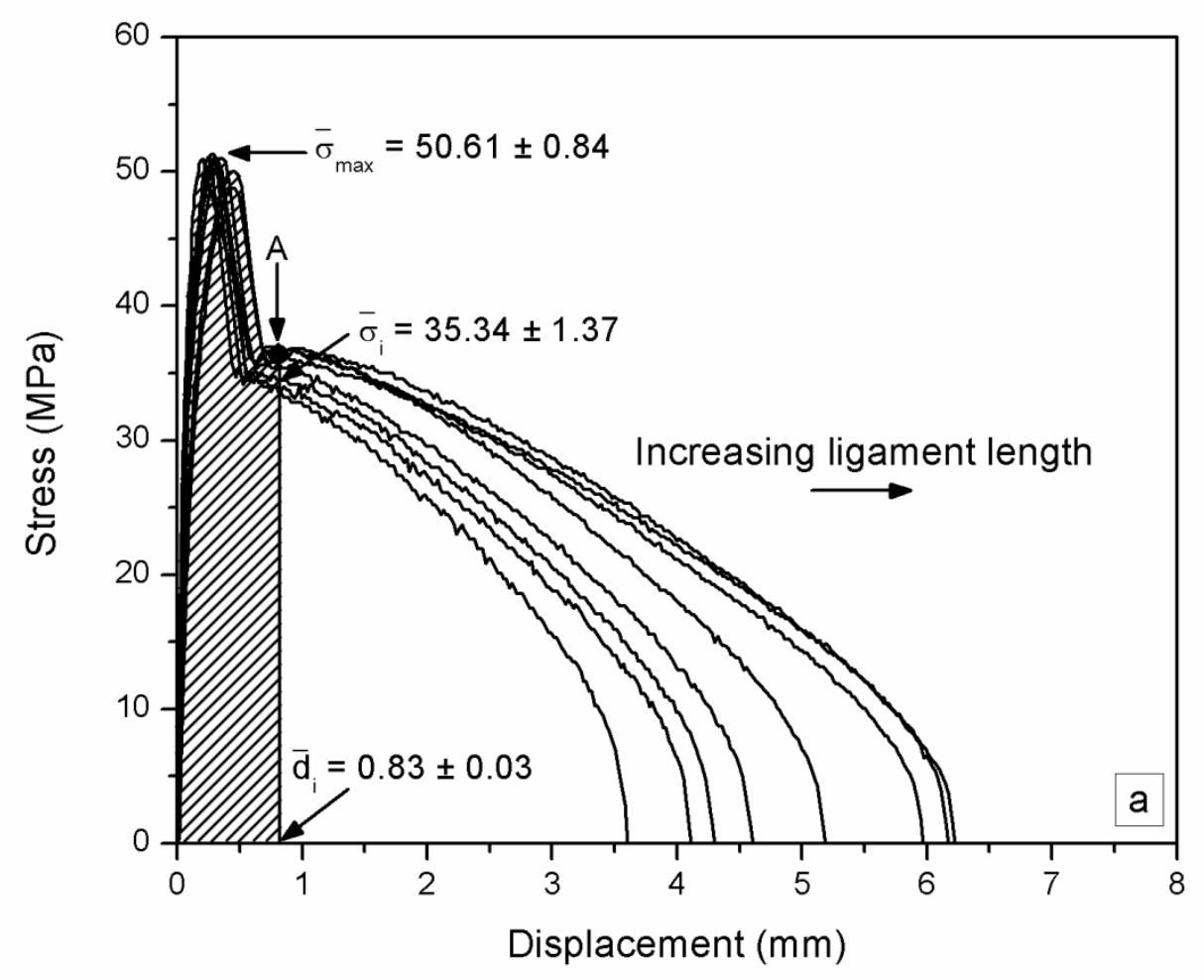

Figure $7 a$ 


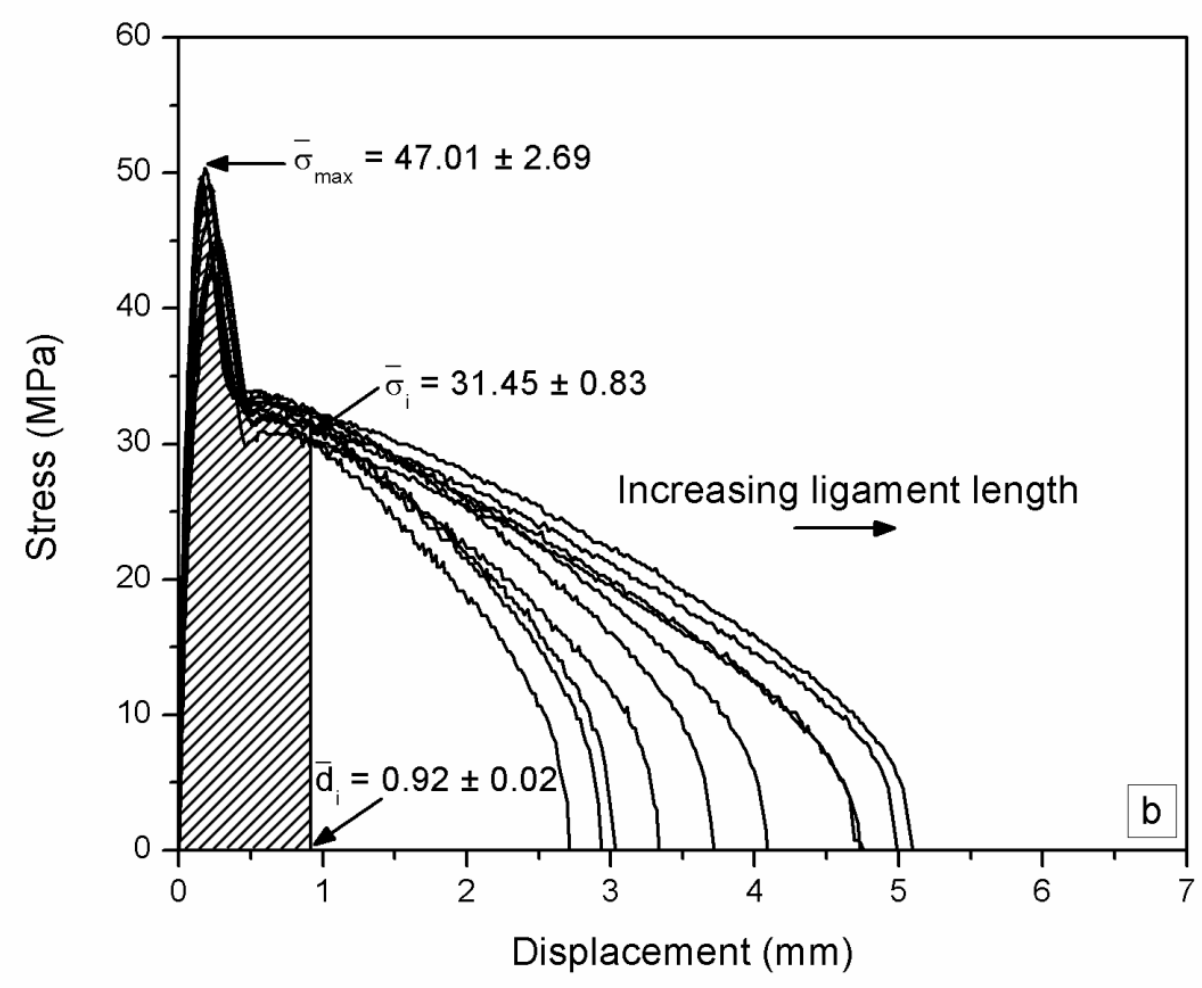

Figure $7 b$ 


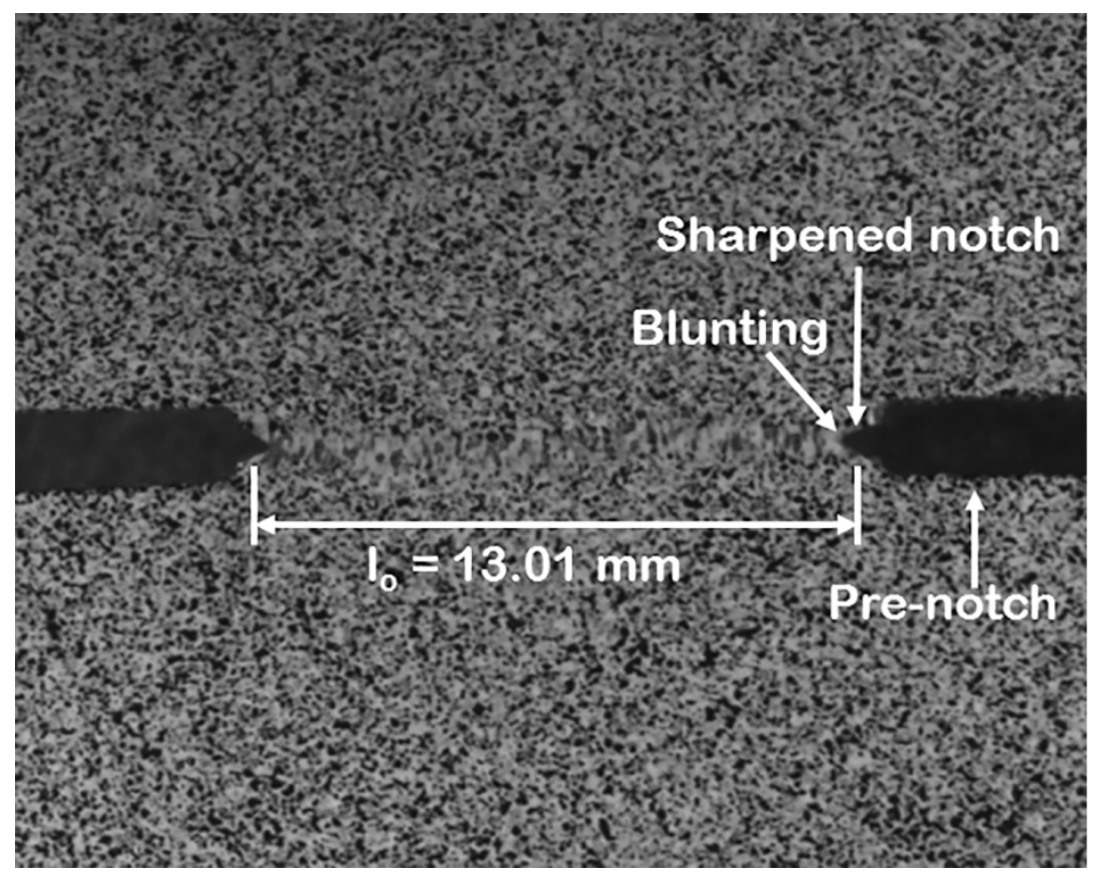

Figure 8 


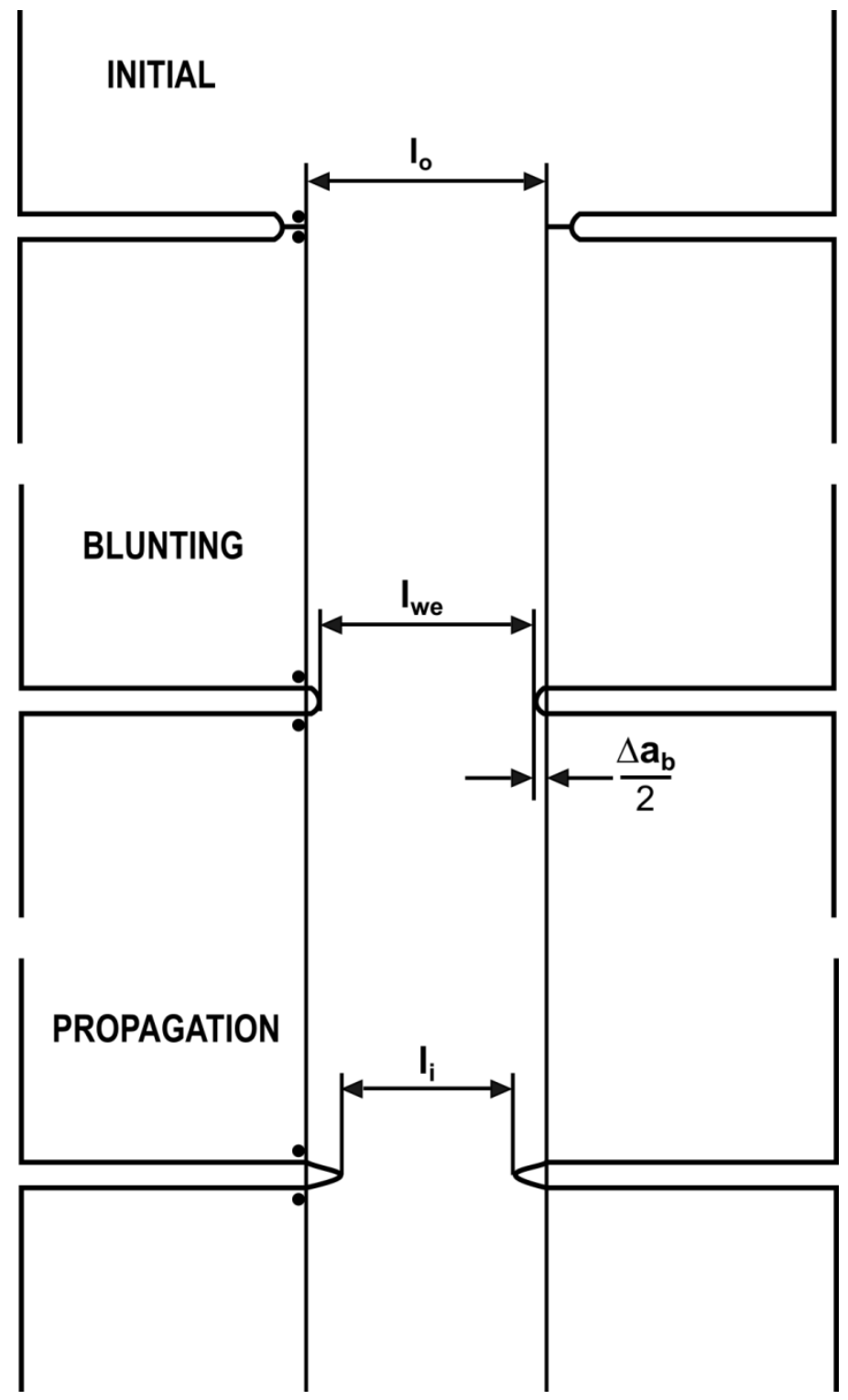

Figure 9 


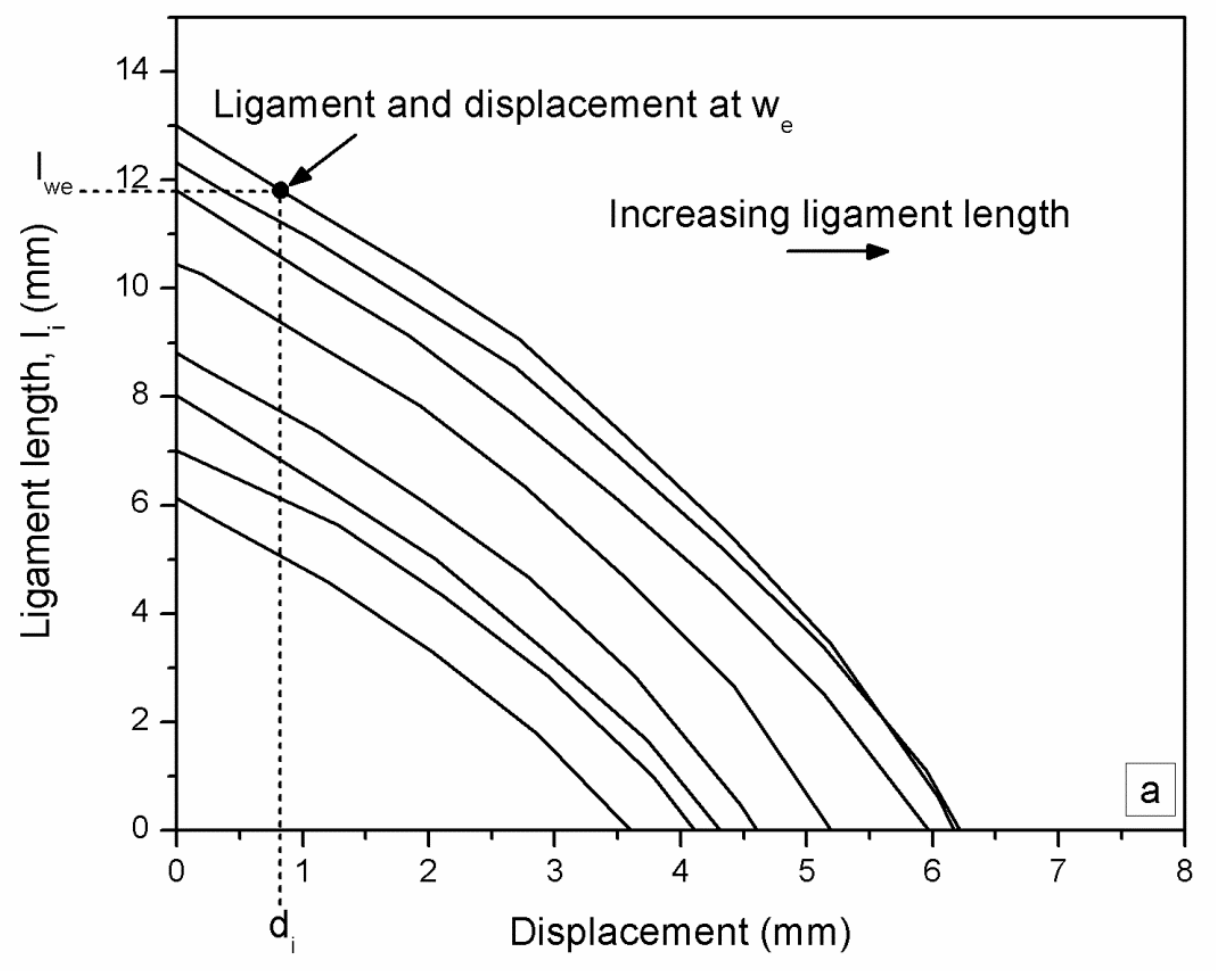

Figure 10a 


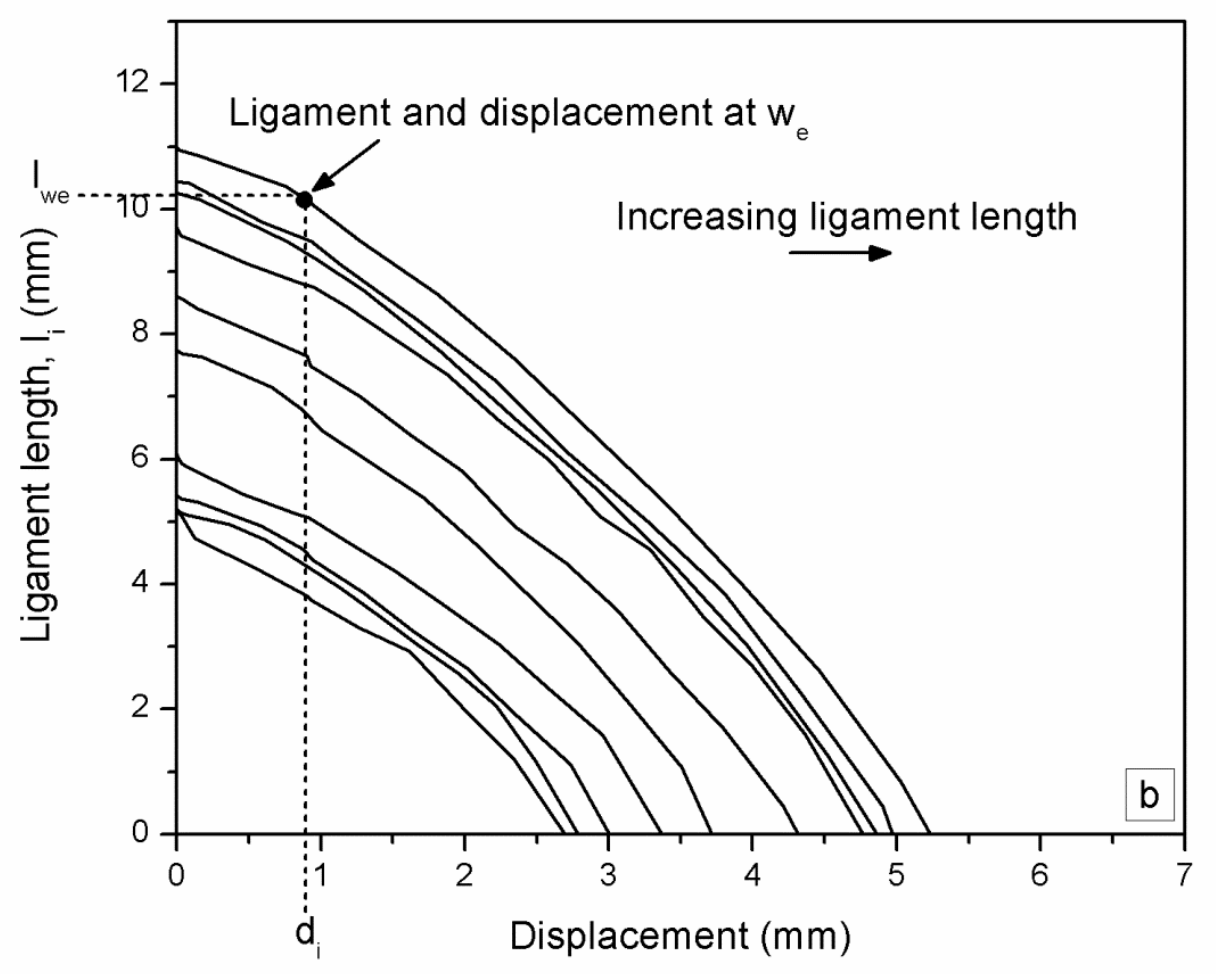

Figure 10b 


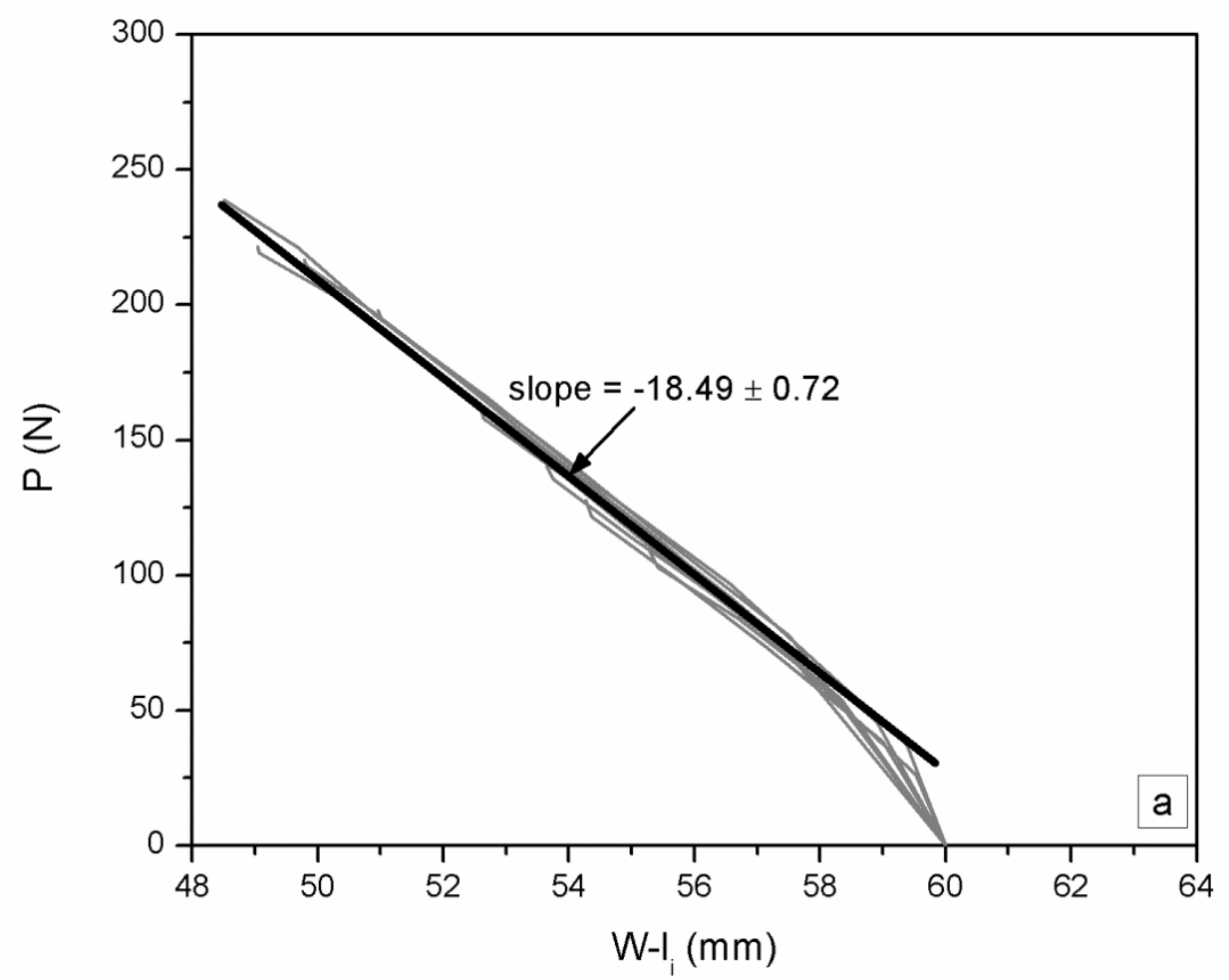

Figure 11a 


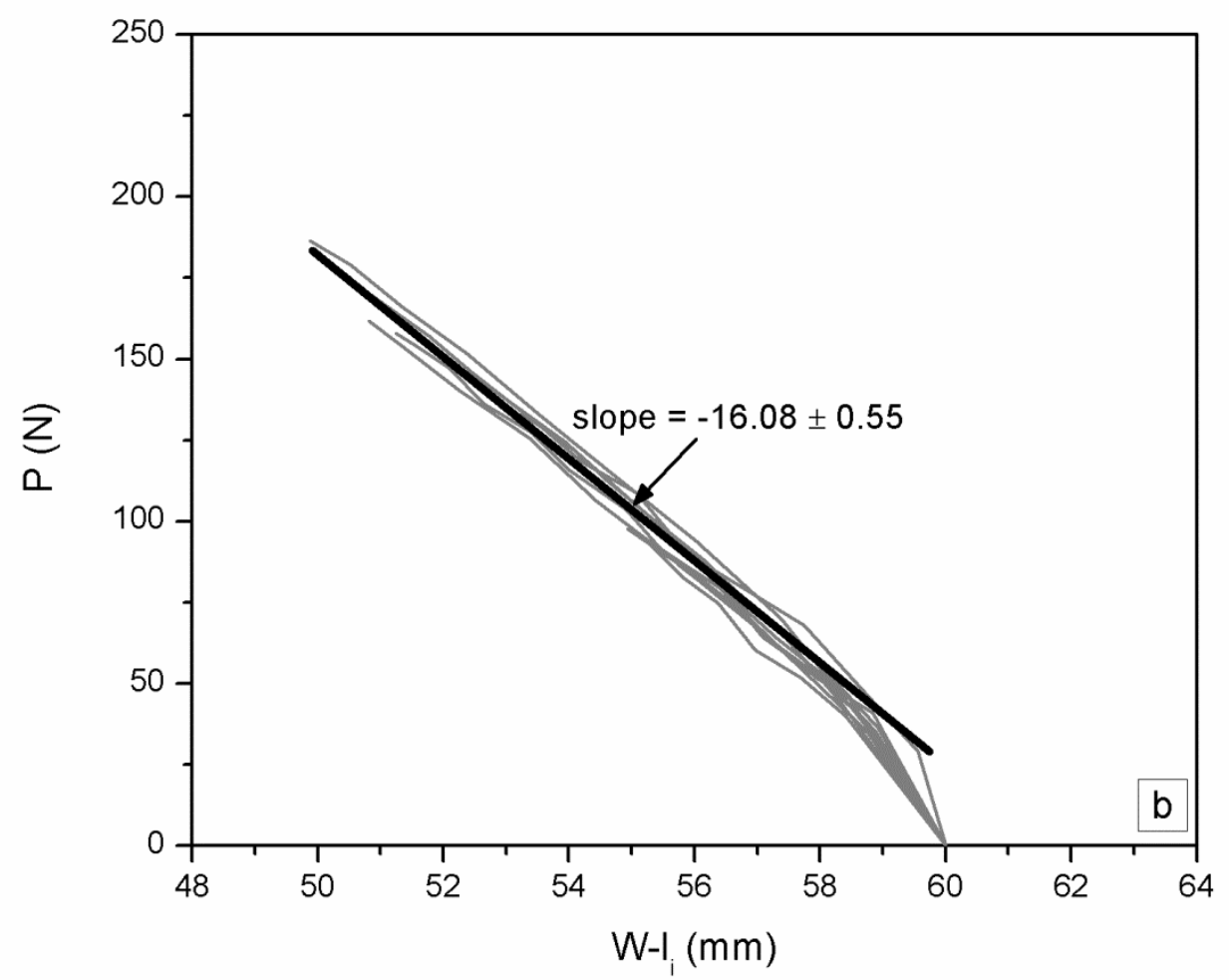

Figure $11 b$ 


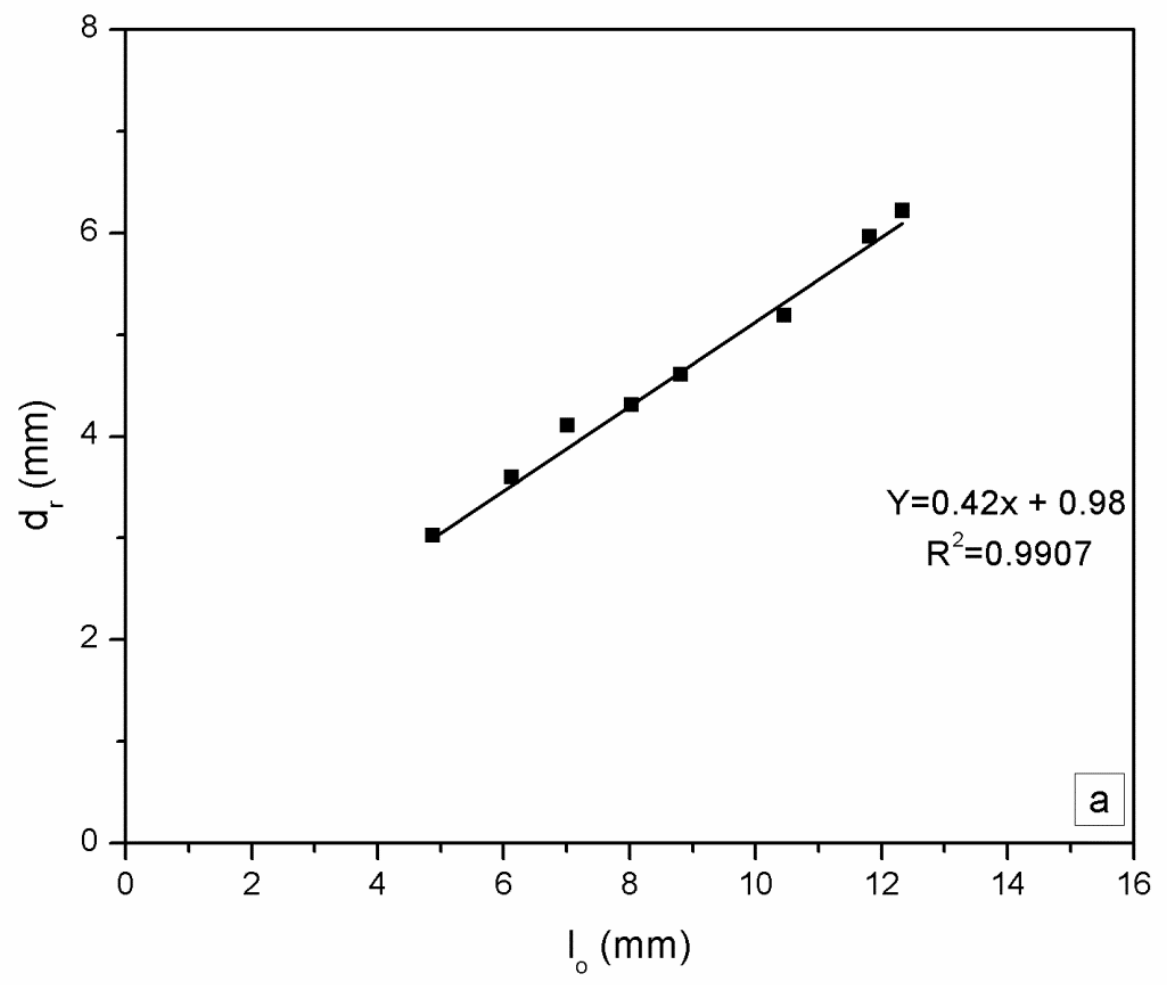

Figure $12 a$ 


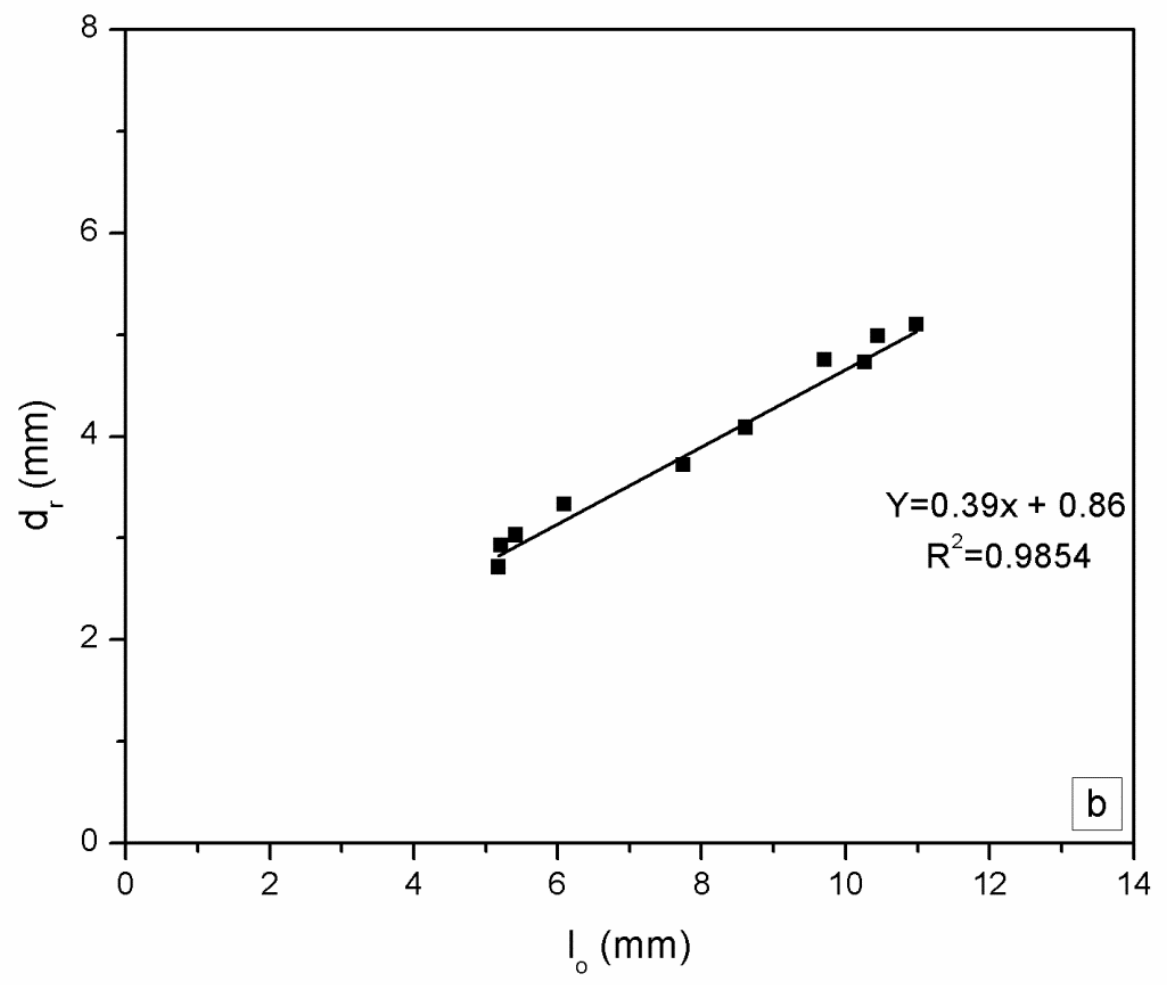

Figure 12b 


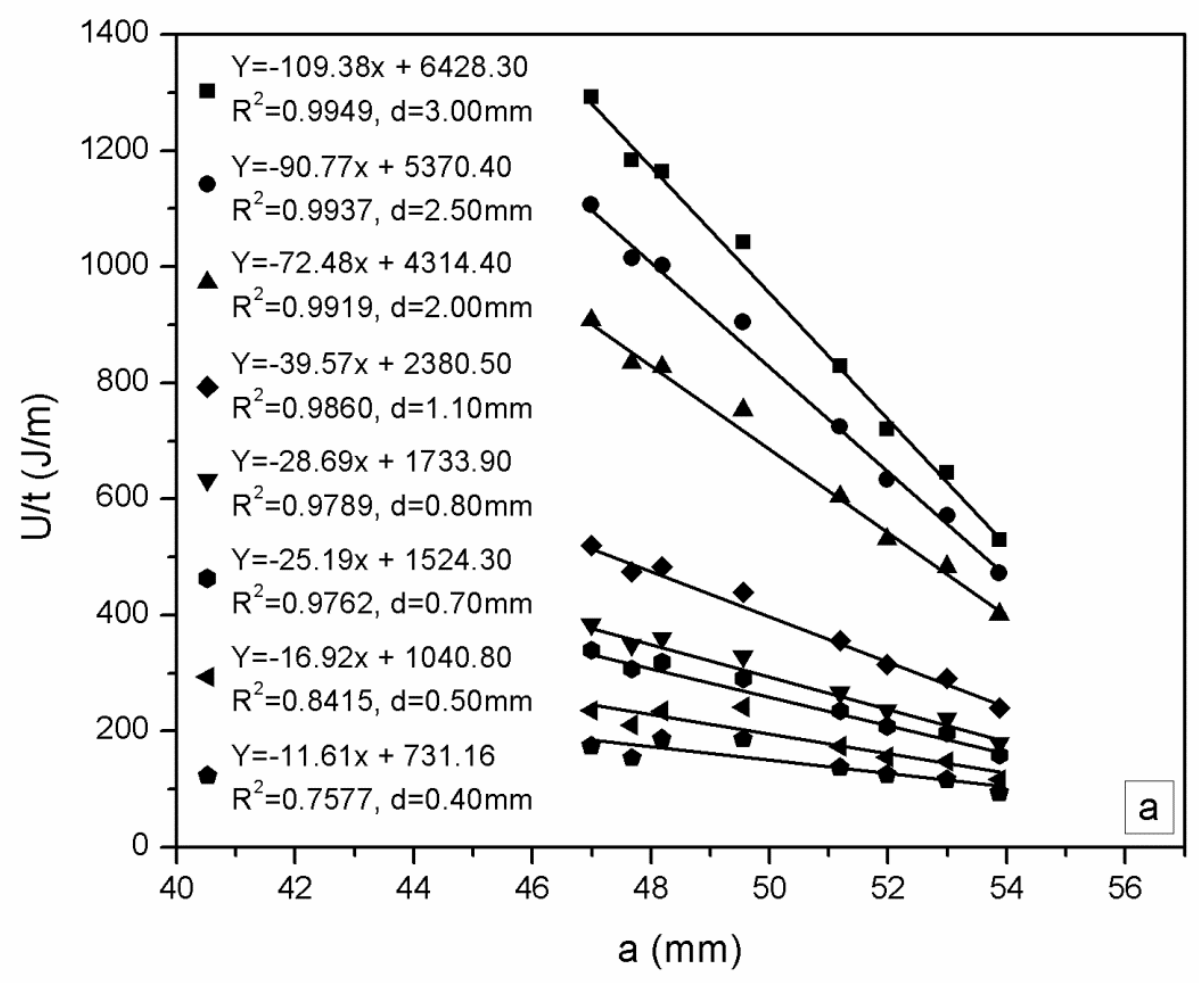

Figure 13a 


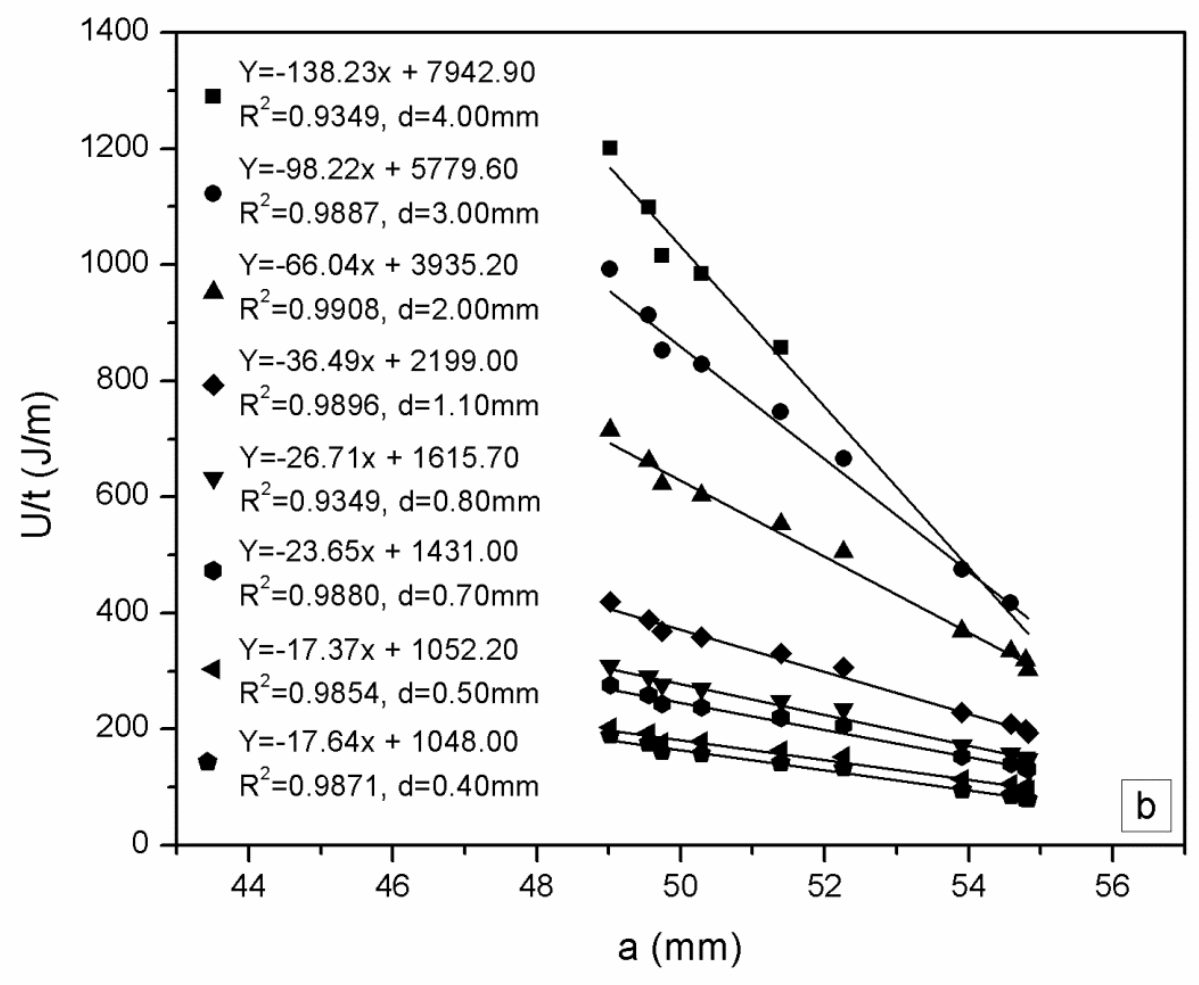

Figure 13b 


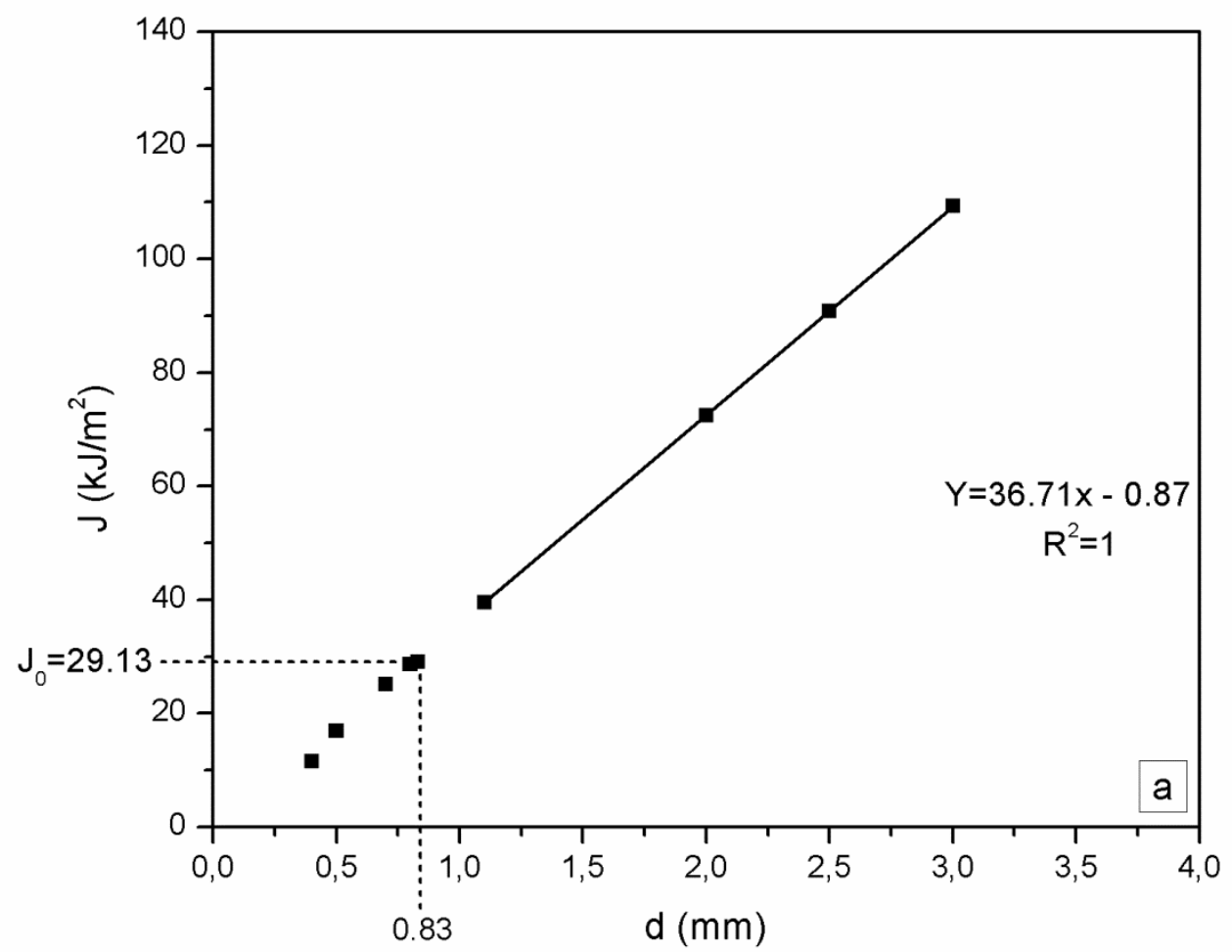

Figure $14 a$ 


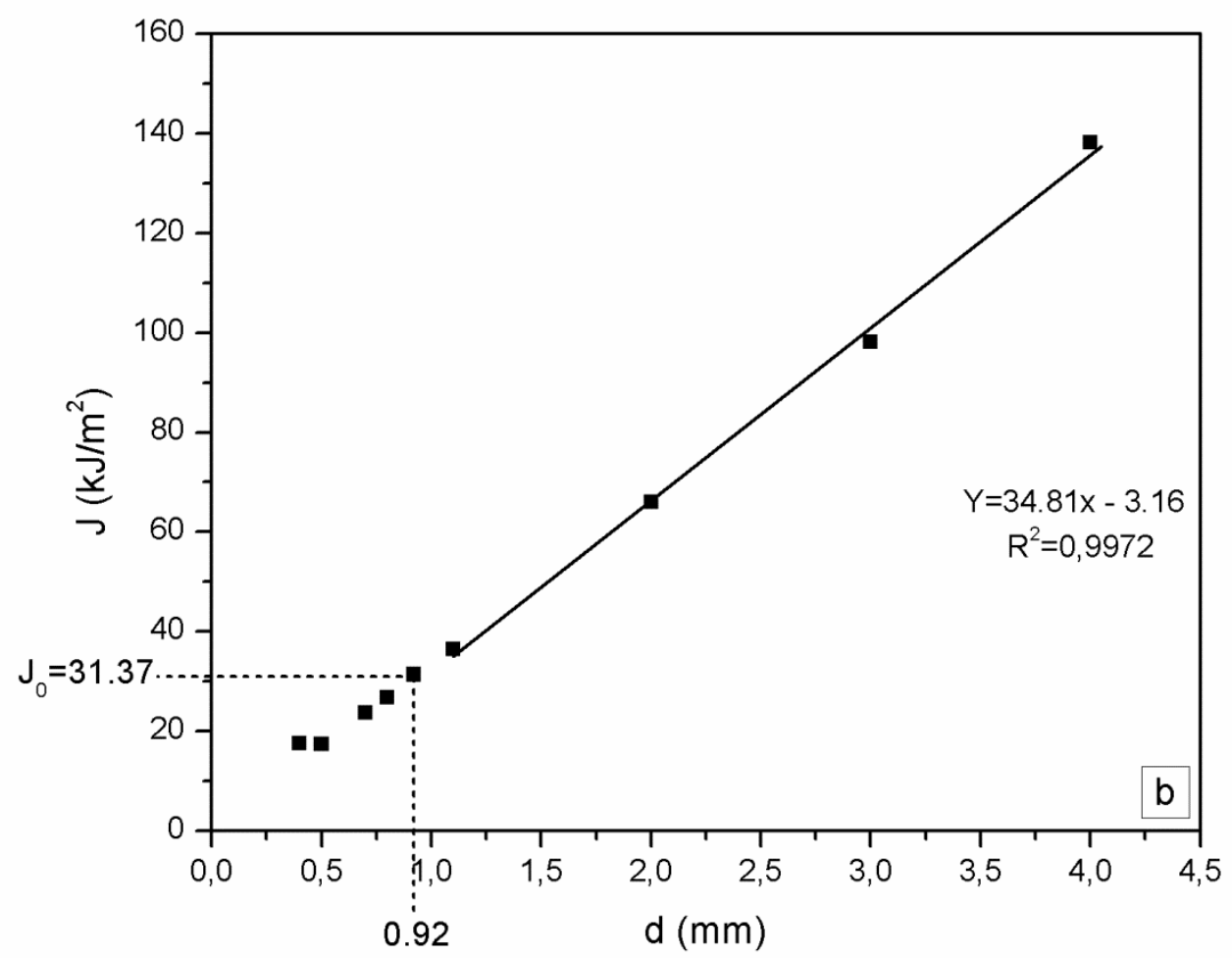

Figure 14b 